\title{
Perspectiva X Realidade: Um Estudo sobre os Campos de Atuação dos Discentes e Egressos do Curso de Licenciatura em Computação
}

\author{
Title: Expectation X Actuality: A Study on playing fields of Students and Graduates from the \\ Computer Science Degree Course
}

Lucas Luan de Araújo Freitas Universidade Estadual do Ceará

lucas.luan@aluno.uece.br

\author{
Sávio Freire \\ Instituto Federal do Ceará \\ savio.freire@ifce.edu.br
}

\begin{abstract}
Resumo
Embora o egresso do curso de licenciatura em computação possua uma formação multidisciplinar, a identificação dos campos de atuação esperados por seus licenciandos e ocupados por seus egressos ainda requer investigação para auxiliar na melhoria do curso, integrando as necessidades dos alunos, do curso e do mundo do trabalho. $O$ presente trabalho tem como objetivo desvelar os campos de atuação esperados pelos licenciandos em Computação e os ocupados pelos egressos do referido curso. Para tanto, o presente estudo coletou e analisou dados de 25 licenciandos e egressos do referido curso. Os resultados mostraram que o ponto de vista dos participantes sobre os campos de atuação é bem similar. Além disso, campos de atuação não reportados na literatura também foram identificados. Espera-se que os resultados possam prover discussões para consolidar a identidade dos egressos do curso de licenciatura em Computação em relação à sua ocupação profissional.
\end{abstract}

Palavras-Chave: Licenciatura em Computação; Campos de Atuação; Visão dos Licenciandos; Visão dos Egressos

\begin{abstract}
Although the graduate of the computer science degree course has a multidisciplinary background, identifying the playing fields expected by its undergraduates and occupied by its graduates still requires research to help improve the course, integrating the needs of students, the course, and the world work. The present work has as objective to identify the playing fields expected by the undergraduates in the computer science degree course and those occupied by the graduates of that course. The present study collected and analyzed data from 25 undergraduates and graduates of that course. The results showed that the participants' point of view on the playing fields is similar. Also, we identified playing fields not reported in the literature. We hope that the results can provide discussions to consolidate the identity of the graduates of the Computer Science degree course concerning their professional occupation. Keywords: Computer Science Degree Course; Playing fields; Undergraduates' Point of View; Graduates' Point of
\end{abstract} View

Cite as: Freitas, L.L.A., \& Freire, S. (2021). Expectation X Actuality: A Study on playing fields of Students and Graduates from the Computer Science Degree Course (Perspectiva X Realidade: Um Estudo sobre os Campos de Atuação dos Discentes e Egressos do Curso de Licenciatura em Computação). Brazilian Journal of Computers in Education (Revista Brasileira de Informática na Educação - RBIE), 29, 227-254. DOI: 10.5753/RBIE.2021.29.0.227 


\section{Introdução}

Embora as Tecnologias da Informação e Comunicação (TIC) possam ser utilizadas na educação para tornar o processo de ensino e aprendizagem mais dinâmico, o ambiente escolar ainda possui dificuldade em incluir as TIC nas atividades dando maior significado à sua utilização (AYLA \& ROCHA, 2018). Essa dificuldade é justificada devido à falta de formação técnica e pedagógica dos docentes (PÚBLIO JUNIOR, 2018; PAIVA et al., 2017; RAPKIEWICZ et al., 2004). Diante desse cenário, surge a necessidade de um profissional para atuar nesse contexto.

Devido à sua formação multidisciplinar, os egressos do curso de licenciatura em Computação são capazes de utilizar conjuntamente a inovação tecnológica e as habilidades pedagógicas para desenvolver a interdisciplinaridade das diversas disciplinas que formam o currículo escolar (CRUZ, BECKER \& HINTERHOLZ, 2016; ARAÚJO, 2010; RAPKIEWICZ et al., 2004). Assim, esses egressos podem dar suporte aos outros docentes na utilização efetiva das TIC no processo de ensino e aprendizagem. Dentre as principais atribuições, os licenciados em Computação podem ministrar aulas, principalmente, no Laboratório Escolar de Informática (LEI) disponibilizado nas escolas e exercer funções técnicas desenvolvidas em empresas de desenvolvimento e/ou manutenção de software (ARAÚJO, 2010).

Ainda que o perfil do egresso do curso de Licenciatura em Computação seja descrito pela Sociedade Brasileira de Computação (SBC) (LUCIANO \& SANTOS, 2013), os egressos ainda enfrentam dificuldades em relação à sua identidade (SANTOS, SILVA \& HINTERHOLZ, 2017; CASTRO \& VILARIM, 2013). Dentre elas, a inserção no mundo do trabalho após a conclusão do curso ainda precisa ser superada, requerendo investigações sobre quais são os campos de atuação ocupados pelos egressos. Além disso, identificar os campos de atuação esperados pelos alunos do curso também pode auxiliar na melhoria do curso, integrando as necessidades dos alunos, do curso e do mundo do trabalho.

Alguns trabalhos relacionados têm buscado identificar quais os campos de atuação ocupados pelos licenciados em Computação (TEIXEIRA, 2019; FREITAS \& FREIRE, 2018; AYLA \& ROCHA, 2018; ROMERO, 2017; LUCIANO \& SANTOS, 2013; RAPKIEWICZ et al., 2004). Entretanto, somente o trabalho de (ROMERO, 2017) investigou a visão dos alunos e egressos sobre os campos de atuação desejáveis e ocupados, porém os autores não analisaram os dois perfis de forma separada. Os demais trabalhos focam na identificação das funções desempenhadas pelos egressos utilizando questionários como instrumento de coleta de dados. Embora esses trabalhos revelem as funções desempenhadas pelos egressos, apenas o nosso estudo preliminar (FREITAS \& FREIRE, 2018) fez comparações com o Projeto Pedagógico do Curso (PPC) para identificar se os campos de atuação esperados pelo PPC foram de fato ocupados no mundo do trabalho. Logo, mais investigação é necessária para identificar a visão dos licenciandos e verificar se existe diferença entre as perspectivas dos licenciandos e dos egressos sobre os campos de atuação.

O objetivo da presente pesquisa, portanto, é desvelar os campos de atuação esperados pelos licenciandos em Computação e os ocupados pelos egressos do referido curso. Para tanto, foram aplicados questionários para os licenciandos e egressos do curso de licenciatura em Computação ofertado pela Universidade Estadual do Ceará (UECE) no polo presencial situado em Mauriti/Ceará. Em seguida, análises de dados qualitativa e quantitativa foram executadas para identificar e comparar os campos de atuação esperados e ocupados pelos licenciandos e egressos, respectivamente.

Os resultados mostram que, embora os campos de atuação esperados e ocupados sejam semelhantes, os licenciandos em Computação esperam atuar principalmente na "organização e administração de laboratórios de informática" e na "capacitação de professores e comunidade escolar, segundo critérios da escola para trabalhar com informática educativa”, os egressos do referido curso tem ocupado postos no mundo do trabalho principalmente que focam na 
"organização e administração de laboratórios de informática". Além disso, outros campos de atuação foram identificados no presente trabalho, confirmando e estendendo os resultados reportados nos trabalhos relacionados.

Espera-se que os resultados da presente pesquisa possam direcionar melhorias na matriz curricular do curso de licenciatura em Computação analisado, convergindo as expectativas dos licenciandos com os reais campos de atuação ocupados pelos egressos do referido curso. Além disso, espera-se que o resultados também possam servir como pontos de discussões para consolidar a identidade dos egressos do referido curso.

Este artigo está organizado como segue. A Seção 2 apresenta o perfil do licenciado em Computação, a dificuldade de atuação enfrentado por esse licenciado e o curso ofertado pela UECE. Os trabalhos relacionados são discutidos na Seção 3. Em seguida, o método de pesquisa é detalhado na Seção 4. Os resultados alcançados e a discussão sobre esses resultados são apresentados nas Seções 5 e 6, respectivamente. A Seção 7 discute as limitações do estudo. Finalmente, as considerações finais são apresentadas na Seção 8.

\section{Fundamentação Teórica}

Essa seção apresenta o perfil do licenciado em Computação, discute sobre a sua dificuldade de atuação e apresenta o curso ofertado pela UECE.

\subsection{O Perfil do Licenciado em Computação}

O licenciado em Computação é um profissional capaz de utilizar conjuntamente a inovação tecnológica e as habilidades pedagógicas para desenvolver a interdisciplinaridade no currículo escolar (ARAÚJO, 2010; RAPKIEWICZ et al., 2004). Essa interdisciplinaridade traz um maior dinamismo para o processo de ensino e aprendizagem. Para tanto, o curso de licenciatura em Computação integra a área da Computação à diversas áreas, como a Educação, Matemática e Filosofia, formando um professor multidisciplinar (CRUZ, BECKER \& HINTERHOLZ, 2016).

Por meio dessa multidisciplinaridade, o licenciado em Computação pode atuar em diversas áreas, desde a sua função como docente buscando a integração e interdisciplinaridade sobre o uso das TIC como também na construção e desenvolvimentos de softwares educativos (MATOS \& SILVA, 2012). Auxiliar na formação dos outros docentes para a utilização das TIC no processo de ensino e aprendizagem também é função desses licenciados (ARAÚJO, 2010). Essa atuação é descrita no Currículo de Referência para Cursos de Licenciatura em Computação elaborado pela SBC (LUCIANO \& SANTOS, 2013).

De forma mais prática, é de suma importância que o profissional com formação em licenciatura em computação saiba como operar sistemas de software e as demais TIC, mas também é preciso que tenha conhecimentos de outras áreas que fazem parte do fazer pedagógico para que assim possa exercer suas funções além do LEI, pois possuem aptidão de trabalhar com máquinas e pessoas (ARAÚJO, 2010).

\subsection{A Dificuldade de Atuação do Licenciado em Computação}

Mesmo com a definição do perfil dos egressos do curso de licenciatura em Computação pela SBC (LUCIANO \& SANTOS, 2013), a carreira desse profissional ainda não está plenamente construída, enfrentando dificuldades em relação à sua identidade (SANTOS, SILVA \& HINTERHOLZ, 2017; CASTRO \& VILARIM, 2013). Uma dessas dificuldades é o pouco conhecimento que empresas e escolas têm sobre o papel do licenciado em Computação (QUEIROZ, SANTOS \& RODRIGUES, 2016; SANTOS et al., 2016), dificultando a inserção desses licenciados no mundo do trabalho. 
Nesse sentido, o estudo conduzido por (SANTOS, SILVA \& HINTERHOLZ, 2017) obteve 54 respostas válidas de egressos do curso de licenciatura em Computação e evidenciou que o maior desafio dos licenciandos em Computação era encontrar uma vaga na área de Computação ou Informática na Educação. Além disso, mais da metade desses egressos nunca haviam trabalhado na área. Os autores ainda perceberam que, mesmo existindo um crescimento de vagas para os egressos do curso, o desconhecimento sobre o papel de atuação pode ser um fator limitante para a ocupação dessas vagas pelos egressos do curso.

No manifesto organizado por (OLIVEIRA et al., 2020), foi constatado que alguns concursos públicos não ofertaram vagas para licenciados em Computação para o perfil de professor de Computação na Educação Básica, confirmando a percepção de (SANTOS, SILVA \& HINTERHOLZ, 2017) sobre o desconhecimento do perfil do profissional licenciado em Computação. O manifesto listou os principais desafios enfrentados pela licenciatura em Computação e propôs ações para mitigá-los. A atuação profissional é listada com um desses desafios e uma ação de enfrentamento seria garantir os direitos dos licenciados para a correta oferta de vagas e fomentar o preenchimento delas pelos licenciados.

Com isso, nota-se que tanto o perfil quanto a atuação profissional dos licenciados em Computação são pontos de discussões pela comunidade acadêmica, buscando por soluções que possam incluir esses profissionais nas vagas de trabalho que devem, de fato, ser ocupadas por eles. Nesse sentido, pesquisas que desvelem os campos de atuação ocupados pelos egressos do curso de licenciatura em Computação podem colaborar para a definições de ações que visem melhorar a inserção desses egressos no mundo do trabalho.

\subsection{O Curso ofertado pela UECE}

A UECE vem ofertando o curso de licenciatura em Computação, na modalidade Educação a Distância (EaD) em parceria com a Universidade Aberta do Brasil (UAB) para atender à demanda de formação de professores para a rede pública de ensino. Inicialmente, o curso de licenciatura em Informática foi implantado em 2008 (BASTOS \& FELIPE, 2014), porém em 2014, o PPC do curso foi alterado e passou a denominar-se Licenciatura em Computação.

De acordo com o PPC do referido curso, o seu objetivo é

"propiciar uma formação sólida e abrangente de educadores, com base nas áreas de computação e técnicas de informática, enfatizando aspectos científicos, técnicos, pedagógicos e sociais; Visa a geração de inovações no processo da formação de educadores para a educação básica, preparando-os para o exercício do magistério suportado por tecnologias de informática e fundamentos de computação" (BASTOS \& FELIPE, 2014, p. 77).

Com isso, o curso visa:

“(i) habilitar professores para o ensino de informática, dentro da concepção de educação e de ensino-aprendizagem a distância, com ênfase na reflexão crítica e na construção do conhecimento; (ii) evidenciar as relações e inter-relações entre a sociedade e o contexto da educação profissional em sua natureza e em suas implicações políticas e ideológicas; (iii) oportunizar a aquisição de competências teórico-metodológicas e tecnológicas para o exercício da prática docente no ensino da informática; e (iv) discutir a situação das escolas profissionais (BASTOS \& FELIPE, 2014, p. 77).”

O curso foi estruturado nos seguintes eixos curriculares:

- Núcleo de formação básica, que compreende os princípios básicos da área de Computação; 
- Núcleo de formação tecnológica, que possibilita aplicar os conhecimentos básicos no desenvolvimento tecnológico da Computação;

- Núcleo de formação humanística, que permitem a formação na dimensão social e humana;

- Núcleo comum, que engloba conhecimentos teóricos e práticos, abordados pelas disciplinas instrumentais;

- Núcleo pedagógico, que permite que o aluno diversifique suas opções, se envolvendo formalmente com outros tipos de atividades, como Atividades Científico-Culturais Complementares (ACC) e Prática como Componente Curricular (PCC);

- Estágio supervisionado, no qual está presente a efetivação da integração teoriaprática e o aprofundamento da relação ação-reflexão-ação; e

- Trabalho de Conclusão de Curso (TCC), no qual o aluno terá que elaborar um trabalho original, a partir das experiências vivenciadas nas disciplinas de Estágio Supervisionado nos Ensino Fundamental ou no Ensino Médio, em forma de monografia ou artigo científico.

Diante do exposto, pode-se caracterizar o profissional da área desse curso como

“[...] um educador, capacitado para o ensino de computação e informática no ensino fundamental, médio e profissionalizante; detém uma formação favorecida pela utilização da informática educativa. É um profissional com sólida e ampla qualificação científica e pedagógica, capacitado a acompanhar a evolução das novas tecnologias na área de computação e informática educacional” (BASTOS \& FELIPE, 2014, p. 70).

Mais especificamente, o perfil do egresso do referido curso deve ser um "educador capacitado para o ensino de computação e informática nos níveis Fundamental, Médio e Profissionalizante", ter formação em Informática Educativa" e ser "qualificado de forma ampla e sólida nas áreas científica e pedagógica". Além disso, deve possuir as seguintes habilidades (i) ampla formação tecnológica em computação (conceitual e prática) e (ii) habilitado a desenvolver e implementar produtos e soluções de informática voltada ao ensino e treinamento, como software educativo e sistemas $\mathrm{EaD}$.

Adicionalmente, o PPC indica que o profissional formado pelo referido curso pode atuar nos seguintes campos de atuação:

- Pesquisa em tecnologia na área da Informática,

- Criação, utilização e avaliação de software educacional,

- Elaboração e participação em projetos na área de $\mathrm{EaD}$,

- Desenvolvimento de materiais instrucionais através do emprego da informática,

- Organização e administração de laboratórios de informática,

- Assessoria às instituições educativas que constroem Propostas Pedagógicas,

- Capacitação de professores e comunidade escolar, segundo critérios da escola para trabalhar com informática educativa, e

- Elaboração de materiais didático-pedagógicos.

\section{Trabalhos Relacionados}

Nessa seção, inicialmente, são apresentados os trabalhos relacionados ao objetivo da presente pesquisa. Em seguida, nosso estudo preliminar é detalhado. 


\subsection{Estudos sobre os Campos de Atuação}

A pesquisa conduzida por (RAPKIEWICZ et al., 2004) buscou justificar a necessidade da criação de um curso de licenciatura em Computação na região Norte Fluminense baseando-se em estudos que traçavam o perfil da região. Os autores identificaram que os professores da região precisavam de suporte para incluir as TIC nas suas aulas, mesmo que a maioria deles tenha aprendido a utilizar a informática na própria escola que trabalham. Além disso, os professores que atuavam no LEI não possuíam formação específica. Em relação aos postos de trabalhos, os autores indicaram que os egressos do curso poderiam atuar como "professores de Informática e Computação", "poderiam proporcionar treinamentos e dar suporte aos professores para a utilização das TIC" e "atuar no treinamento corporativo".

(LUCIANO \& SANTOS, 2013) conduziram uma pesquisa com egressos do curso de licenciatura em Computação do Campus I da Universidade Estadual da Paraíba com o intuito de avaliar os caminhos percorridos por esses egressos. Por meio de aplicação de questionário, 47 egressos do referido curso participaram da pesquisa. Como resultados, os autores conseguiram traçar o perfil dos egressos verificando se eles continuaram os seus estudos, se atuaram como pesquisadores, se estavam empregados e quais as áreas de atuação. Sobre as áreas de atuação, os autores encontraram que os egressos atuaram na "educação presencial", "na EaD", "no desenvolvimento WEB", "na manutenção e suporte de computadores", "no desenvolvimento de software", "no treinamento coorporativo", e "no gerenciamento de projetos".

Com o objetivo de identificar os campos de atuação dos concluintes e egressos do curso de licenciatura em Computação ofertado pela Universidade Federal de Grande Dourados, (ROMERO, 2017) aplicou um questionário contendo sete questões. No total, 79 estudantes responderam ao questionário. Como resultados, os autores identificaram que menos da metade dos estudantes eram egressos do curso e somente 46 deles trabalharam ou estavam trabalhando. Considerando somente esses 46 estudantes, os autores identificaram que $\sim 61 \%$ dos postos de trabalhos estavam fortemente relacionado ao curso. Adicionalmente, os tipos de atividades exercidos eram "administrativo", "docência", "gestão", "docência e administrativa", "coordenadora de polo e de curso técnico EaD", "inspetor de alunos", "manutenção e programação de computadores", "manutenção de computadores", "tecnológico" e "vendas autônomas".

A investigação de (AYLA \& ROCHA, 2018) objetivou apresentar a opinião dos egressos sobre o campo de atuação dos profissionais de licenciatura em Computação formados pela Faculdade de Educação a Distância da Universidade Federal da Grande Dourados. Por meio de questionário, 35 egressos participaram da pesquisa. Como resultados, os autores identificaram que os egressos atuavam ou pretendiam atuar na área educacional, porém o foco principal era "ser um técnico que gerencia tecnologias". Já (TEIXEIRA, 2019) aplicou um questionário para 60 egressos do curso de licenciatura em Computação. Além de traçar o perfil dos participantes, foi identificado que a maioria dos egressos teve dificuldade na inserção profissional e que mais da metade dos egressos atuam no ensino de Computação. Entretanto, a autora não identificou as atividades demais atividades que os egressos estavam desempenhando nos seus postos de trabalho.

O Quadro 1 apresenta a síntese dos trabalhos detalhados anteriormente. Embora seja notório o esforço dos pesquisadores em analisar os campos de atuação dos licenciandos e egressos do curso de licenciatura em Computação, somente o trabalho de (ROMERO, 2017) abordou a visão tanto dos estudantes quanto dos formados, mas de forma conjunta. Consequentemente, não é possível separar os campos de atuação desejáveis dos ocupados. Os demais trabalhos revelam as funções que os egressos têm ocupado no mundo do trabalho sem analisar se essas funções eram ou não esperadas pelo PPC cursado por esses egressos. Investigar essa relação pode auxiliar na melhoria dos cursos de licenciatura em Computação incluindo ou atualizando sua matriz curricular para desenvolver novas competências ou habilidades requeridas pelo mundo do trabalho. Além disso, essa relação também pode proporcionar ações no sentido contrário, ou seja, 
identificar como os licenciados em Computação poderiam ocupar funções no mundo do trabalho que estão definidas na sua formação.

Com base nos trabalhos apresentados, o presente trabalho investiga sobre a relação entre campos de atuação esperados e ocupados, relacionando esses campos aos esperados pelo PPC do curso em análise. Além disso, na Seção 6.3 Comparação com os Trabalhos Relacionados, é apresentada uma comparação entre os achados do presente trabalho com os reportados pelos trabalhos relacionados.

Quadro 1: Síntese dos trabalhos relacionados.

\begin{tabular}{|c|c|c|}
\hline Trabalho & $\begin{array}{l}\text { Quantidade de } \\
\text { participantes }\end{array}$ & Função \\
\hline $\begin{array}{l}\text { RAPKIEWICZ et al., } \\
2004\end{array}$ & - & $\begin{array}{l}\text { - Professores de Informática e Computação, } \\
\text { - Ministrar treinamentos e dar suporte aos professores para a } \\
\text { utilização das TIC, } \\
\text { - Ministrar treinamento corporativo. }\end{array}$ \\
\hline $\begin{array}{l}\text { LUCIANO \& SANTOS, } \\
2013\end{array}$ & 47 egressos & $\begin{array}{l}\text { - Educação presencial, } \\
\text { - Educação a distância, } \\
\text { - Desenvolvimento WEB, } \\
\text { - Manutenção e suporte de computadores, D } \\
\text { - Desenvolvimento de software, } \\
\text { - Treinamento coorporativo, e } \\
\text { - Gerenciamento de projetos. }\end{array}$ \\
\hline ROMERO, 2017 & $\begin{array}{l}46 \text { licenciandos } \\
\text { e egressos }\end{array}$ & $\begin{array}{l}\text { - Administrativa, } \\
\text { - Docência, } \\
\text { - Gestão, } \\
\text { - Docência e administrativa, } \\
\text { - Coordenadora de polo e de curso técnico EaD, } \\
\text { - Inspetor de alunos, } \\
\text { - Manutenção e programação de computadores, } \\
\text { - Manutenção de computadores, } \\
\text { - Tecnológico, e } \\
\text { - Vendas autônomas. }\end{array}$ \\
\hline AYLA \& ROCHA, 2018 & 35 egressos & - Ser um técnico que gerencia tecnologias. \\
\hline TEIXEIRA, 2019 & 60 egressos & \\
\hline
\end{tabular}

\subsection{Estudo Preliminar}

Em nosso estudo preliminar (FREITAS \& FREIRE, 2018), foi realizada uma pesquisa com 12 egressos do curso de licenciatura em Computação ofertado pela UECE no polo presencial situado em Mauriti/Ceará. Por meio da aplicação de um questionário, foi possível verificar se os campos de atuação ocupados pelos egressos correspondiam aos indicados no PPC do referido curso. Como principais resultados, foram identificados que os campos de atuação esperados no PPC eram (i) pesquisa em tecnologia na área da Informática, (ii) criação, utilização e avaliação de software educacional, (iii) elaboração e participação em projetos na área de $\mathrm{EaD}$, (iv) desenvolvimento de materiais instrucionais através do emprego da Informática, (v) organização e administração do LEI, (vi) assessoria às instituições educativas que constroem Propostas Pedagógicas, (vii) capacitação de professores e comunidade escolar, segundo critérios da escola para trabalhar com Informática educativa, e (viii) elaboração de materiais didático-pedagógicos. Além disso, foi verificado que pelo menos um egresso ocupou um desses campos de atuação no mundo do trabalho.

Embora o estudo preliminar demostre os campos de atuação ocupados pelos egressos do curso ofertado pela UECE, a perspectiva dos licenciandos em Computação não é abordada. Nesse sentido, o presente trabalho estende o estudo preliminar, incluindo: 
- A percepção dos licenciandos do referido curso capturada por meio de questionário,

- A comparação entre os campos de atuação esperados pelos licenciandos e os ocupados pelos egressos, e

- A comparação entre os achados da presente pesquisa com os descritos nos trabalhos relacionados.

Espera-se que os achados da presente pesquisa possam direcionar melhorias na matriz curricular do curso analisado, proporcionando um melhor entendimento dos licenciandos em Computação sobre os possíveis campos de atuação que eles podem ocupar devido à formação recebida no referido curso.

\section{Método de Pesquisa}

Como esse trabalho envolveu o questionamento direto dos participantes relacionado ao seu objetivo, pode-se enquadrá-lo como um estudo descritivo e de levantamento (JOYE, 2014). Além disso, é de natureza aplicada, pois visa gerar conhecimento para a solução de problemas específicos, tem abordagem qualitativa e quantitativa, e utiliza a aplicação de questionários para a coleta de dados. Para tanto, foram elaboradas questões de pesquisa e procedimentos de coleta e análise de dados.

\subsection{Questões de Pesquisa}

Com o intuito de atingir ao objetivo do presente trabalho, foi definida a seguinte Questão de Pesquisa (QP): “Quais são os campos de atuação esperado pelos licenciandos em Computação e os ocupados pelos licenciados (egressos) em Computação?”. Por meio dessa questão, buscase identificar quais são os campos de atuação esperados e ocupados pelos alunos e egressos do curso de licenciatura em Computação. Essa QP foi dividida nas seguintes subquestões:

QP1: Quais são os campos de atuação esperados pelos alunos do curso de licenciatura em Computação? Essa QP visa identificar quais são as perspectivas dos licenciandos em Computação em relação aos campos de atuação que podem ser ocupados por eles devido à sua formação.

QP2: Quais são os campos de atuação ocupados pelos egressos do curso de licenciatura em Computação? Essa QP tem como finalidade identificar quais os reais campos de atuação que os egressos do curso de licenciatura em Computação têm ocupado devido à formação recebida no referido curso.

\subsection{Coleta de Dados}

A coleta de dados ocorreu por meio da aplicação de dois questionários aos licenciandos e egressos do polo presencial da UECE situado na cidade de Mauriti/Ceará. Um para os licenciandos em Computação e outro para os egressos do mesmo curso. Os dois questionários encontram-se no Apêndices A e B. O objetivo principal dos questionários foi identificar o ponto de vista dos alunos e egressos sobre a área em que estão inseridos e as possibilidades de atuação profissional.

Os questionários foram baseados no PPC do referido curso para que fosse viabilizada a comparação entre os resultados possíveis (PPC), reais (opinião dos formados) e esperados (opinião dos alunos). Em ambos os questionários, foram incluídas questões para (i) caracterizar os participantes, (ii) identificar a relação com as TIC, (iii) identificar a formação recebida no curso, e (iv) descrever as experiências profissionais (estágio ou emprego).

Ambos os questionários foram elaborados no Google forms e disponibilizados via e-mail ou via aplicativos de mensagens instantâneas. Também foram necessárias visitas ao polo para (i) 
expor a importância da colaboração das turmas para obter um maior número de participações dos alunos e (ii) coletar o contato dos egressos que foram disponibilizados pela coordenação do curso.

\subsection{Análise de Dados}

Devido à natureza das questões, foram necessários diferentes procedimentos de análise de dados. Para as questões fechadas, foi quantificado o número de participantes escolhendo uma opção das que estavam disponíveis para cada questão.

Para as questões abertas, foram aplicadas técnicas de análise qualitativa com o intuito de identificar códigos que expressassem a opinião dos participantes (STRAUSS \& CORBIN, 1998). Por exemplo, dois licenciados justificaram sua opinião na primeira questão do questionário (Você considera importante a inserção das Tecnologias da Informação e Comunicação (TICs) no processo de ensino-aprendizagem?) informando que "atualmente é imprescindível o uso das Tecnologias no processo ensino-aprendizagem, o mundo está inteiramente voltado ao seu uso" e "pois, de forma alguma o educador poderá virá as costas para o uso das TICs em sala de aula, já que elas fazem parte do nosso cotidiano, seja de forma simples ou não". Embora as justificativas sejam escritas de formas diferentes, elas possuem o mesmo significado, ou seja, indicam "inserção no cotidiano".

Todo o processo de identificação de código foi realizado pelo primeiro autor e revisado pelo segundo autor. As divergências foram resolvidas por meio de uma reunião entre os dois autores.

\section{Resultados}

Esta seção apresenta os resultados obtidos a partir dos dados coletados. No total, 13 licenciandos e 12 licenciados (egressos) do curso de licenciatura em Computação responderam aos questionários.

\subsection{Campo de Atuação Esperado pelos Licenciandos (QP1)}

Dos 40 alunos regularmente matriculados, somente 13 responderam ao questionário, representando uma amostra de 32,5\% dos licenciandos em Computação. A maioria desses alunos era formada por estudantes do sexo masculino $(\sim 77 \%)$, distribuídos desde o quarto ao oitavo semestre do curso. A faixa etária variava dos 18 aos 33 anos, mas a maioria deles possuía 28 anos.

Inicialmente, os licenciandos foram questionados sobre a importância da inserção das TIC no processo de ensino e aprendizagem. Além de indicar se era importante ou não, eles deveriam também justificar a sua resposta. Todos eles consideram essa inserção importante, "porque com TICs na escola os professores tem (sic) uma nova oportunidade de melhora (sic) o ensino e aprendizagem dos alunos". Essa afirmação corrobora com o entendimento de (MIRANDA, 2007, p.45) que expressa "[...] o professor dominar estas novas ferramentas poderá apoiar os alunos a explorar as potencialidades destes novos sistemas de tratamento e representação da informação". A Tabela 1 apresenta a síntese das justificativas.

Analisando a Tabela 1, é possível perceber que o tópico "novas metodologias de ensino e aprendizagem" foi o mais citado pelos licenciandos, evidenciando que as TIC são capazes de dinamizar as aulas e capturar a atenção dos alunos para o conteúdo de sala de aula. Os tópicos "tecnologia como ferramenta cotidiana" e "adequação às novas tecnologias" também colaboram para esse dinamismo, pois revelam que os licenciandos entendem que as TIC fazem parte do cotidiano de boa parte dos alunos e que o processo de ensino e aprendizagem necessita se adequar a elas. De modo geral, os três tópicos extraídos das justificativas dos licenciandos são complementares e demonstram que eles possuem um entendimento sobre o papel das TIC no processo de ensino e aprendizagem. Esse entendimento é convergente com (XAVIER, TEIXEIRA \& SAVETI, 2010, p.110) que afirmam 
que "o crescimento das TICs e da presença do computador no cotidiano dos lares dos alunos pode também representar boas oportunidades de incorporá-los ao ensino".

Tabela 1: A importância das TIC no processo de ensino e aprendizagem segundo os licenciandos.

\begin{tabular}{|c|l|l|c|}
\hline \multicolumn{1}{|c|}{ Tópico } & \multicolumn{1}{|c|}{ Exemplo de Resposta dos Licenciandos } & $\begin{array}{c}\text { Percentual em relação } \\
\text { ao total de respostas }\end{array}$ \\
\hline 1 & $\begin{array}{l}\text { Novas metodologias de } \\
\text { ensino e aprendizagem }\end{array}$ & "Devido a aula mais interativa e proveitosa." & $41,6 \%$ \\
\hline 2 & $\begin{array}{l}\text { Tecnologia como } \\
\text { ferramenta cotidiana }\end{array}$ & $\begin{array}{l}\text { "Sim pois a tecnologia tem um papel fundamental na } \\
\text { articulação de municípios na troca de experiências e na } \\
\text { construção de saberes que podem ser ministrados a } \\
\text { distância. A tecnologia é também uma forte aliada do } \\
\text { diretor no cotidiano escolar." }\end{array}$ & $33,3 \%$ \\
\hline 3 & $\begin{array}{l}\text { Adequação às novas } \\
\text { tecnologias }\end{array}$ & $\begin{array}{l}\text { "A modernidade nos leva a buscar ainda mais novos } \\
\text { métodos para facilitar a vida humana." }\end{array}$ & $25 \%$ \\
\hline
\end{tabular}

Sobre a formação que estão recebendo no curso, 92,3\% dos licenciandos indicaram que estão sendo capacitados para o ensino de computação e informática nos níveis fundamental, médio e profissionalizante. Os licenciandos indicaram que: "o curso é muito bom e com muitas informações que fazem o aluno pensar e se transformar", porém "o curso precisa de muitos ajustes, principalmente no acompanhamento dos tutores para com o aluno". Além disso, 84,6\% deles acreditam que o curso em EaD formam um profissional apto ao exercício da docência na área da informática educativa. As justificativas revelam que o curso apresenta “(...) um mundo de conhecimento diverso, com ideias novas e potencial ilimitado", mas "o aluno formado precisa ainda buscar melhorar ainda mais porque ainda nem tem a experiência". Com isso, os licenciandos revelam uma preocupação sobre a formação recebida no curso e a demanda no mundo do trabalho.

Em seguida, buscou-se compreender como os licenciandos avaliam as habilidades e competências que estão sendo desenvolvidas por eles no curso. A Tabela 2 apresenta a avaliação dos licenciandos, indicando que a maioria dos licenciandos concorda (totalmente ou parcialmente) que estão (i) adquirindo "ampla formação teórica/prática tecnológica em computação", (ii) desenvolvendo habilidades para "desenvolvimento de software educativo para treinamento", (iii) desenvolvendo habilidades para "desenvolvimento de sistemas EaD para o processo de ensino e para treinamento", e (iv) sendo preparados para "analisar e escolher softwares educativos para a melhoria do processo de ensino e aprendizagem". Entretanto, os licenciandos evidenciaram que a habilidade "desenvolvimento de software educativo para o processo de ensino" não está sendo desenvolvida completamente no curso. Além disso, 84,6\% dos licenciandos indicaram que as disciplinas que compõem a matriz curricular são suficientes para desenvolver as habilidades e competências apresentadas na Tabela 2. Entretanto, os que não concordaram revelaram que deveriam ter disciplinas "mais pedagógicas para entender o aluno e assim obter um resultado para criação de softwares" e "mais voltadas para a criação e desenvolvimento de softwares educativos". Vale ressaltar que a pesquisa não buscou identificar se o desempenho acadêmico poderia impactar na percepção das habilidades e competências.

Os licenciandos também responderam sobre o campo de atuação esperado ao terminar o curso, levando em consideração o que está sendo desenvolvido no decorrer de sua formação, qual o conhecimento que já adquiriram, bem como o que esperam adquirir. A Tabela 3 apresenta os resultados obtidos. É notório que a maioria dos licenciandos esperam atuar na "organização e administração de laboratórios de informática" e na "capacitação de professores e comunidade escolar, segundo critérios da escola para trabalhar com informática educativa", seguida da "assessoria às instituições educativas que constroem Propostas Pedagógicas" e da "elaboração de materiais didático-pedagógicos". 
Tabela 2: Habilidades e competências em desenvolvimento - Visão dos licenciandos.

\begin{tabular}{|c|c|c|c|c|c|}
\hline Habilidades/Competências & DT & DP & IN & $\mathbf{C P}$ & CT \\
\hline Ampla formação teórica tecnológica em computação & 0 & 1 & 0 & 8 & 4 \\
\hline Ampla formação prática tecnológica em computação & 0 & 1 & 1 & 8 & 3 \\
\hline Desenvolvimento de software educativo para o processo de ensino & 2 & 4 & 1 & 2 & 3 \\
\hline Desenvolvimento de software educativo para treinamento & 0 & 1 & 3 & 6 & 3 \\
\hline Desenvolvimento de sistemas EaD (Educação a Distância) para o processo de ensino & 0 & 2 & 0 & 7 & 4 \\
\hline Desenvolvimento de sistemas EaD (Educação a Distância) para treinamento & 1 & 1 & 0 & 7 & 4 \\
\hline $\begin{array}{l}\text { Analisar e escolher softwares educativos para a melhoria do processo de ensino e } \\
\text { aprendizagem }\end{array}$ & 0 & 1 & 1 & 5 & 6 \\
\hline $\begin{array}{ll}\text { Legenda: } & \\
\mathrm{DT}=\text { Discordo totalmente } & \mathrm{DP}=\text { Discordo parcialmente } \\
\mathrm{CP}=\text { Concordo parcialmente } & \mathrm{CT}=\text { Concordo totalmente }\end{array}$ & \multicolumn{5}{|c|}{$\mathrm{IN}=$ Indiferente } \\
\hline
\end{tabular}

Tabela 3: Campos de atuação esperados pelos licenciandos.

\begin{tabular}{|l|c|c|}
\hline \multicolumn{1}{|c|}{ Campos de atuação esperados } & Quantidade & Percentual \\
\hline Organização e administração de laboratórios de informática & 12 & $92,3 \%$ \\
\hline $\begin{array}{l}\text { Capacitação de professores e comunidade escolar, segundo critérios da escola } \\
\text { para trabalhar com informática educativa }\end{array}$ & 12 & $92,3 \%$ \\
\hline Assessoria às instituições educativas que constroem Propostas Pedagógicas & 9 & $69,2 \%$ \\
\hline Elaboração de materiais didático-pedagógicos & 9 & $69,2 \%$ \\
\hline Criação, utilização e avaliação de software educacional & 8 & $61,5 \%$ \\
\hline Elaboração e participação em projetos na área de Ensino a Distância (EAD) & 8 & $61,5 \%$ \\
\hline Desenvolvimento de materiais instrucionais através do emprego da informática & 8 & $61,5 \%$ \\
\hline Pesquisa em tecnologia na área da Informática & 7 & $53,8 \%$ \\
\hline
\end{tabular}

Ainda sobre o campo de atuação, os licenciandos foram questionados sobre o estágio, pois é uma forma de adquirir experiência no mundo do trabalho durante o curso. Dentre eles, 53,8\% informaram que tinham cursado a disciplina de estágio. Os estágios foram realizados principalmente nas escolas de ensino fundamental e médio.

Os licenciandos também indicaram as habilidades que foram desenvolvidas durante o estágio. A Figura 1 apresenta o resultado, indicando que as habilidades "ampla formação teórica tecnológica em computação" e "analisar e escolher softwares educativos para a melhoria do processo de ensino e aprendizagem" foram as mais desenvolvidas pelos licenciandos durante o estágio. Além disso, a Figura 2 mostra os campos de atuação desenvolvidos durante o estágio, conforme indicado pelos licenciandos. É notório que as oportunidades de estágio ocupadas pelos licenciandos enquadrava-se principalmente em "organização e administração de laboratórios de informática" e "pesquisa em tecnologia na área de informática". Entretanto, nenhum dos estágios se enquadrou no "desenvolvimento de materiais institucionais através do emprego da informática".

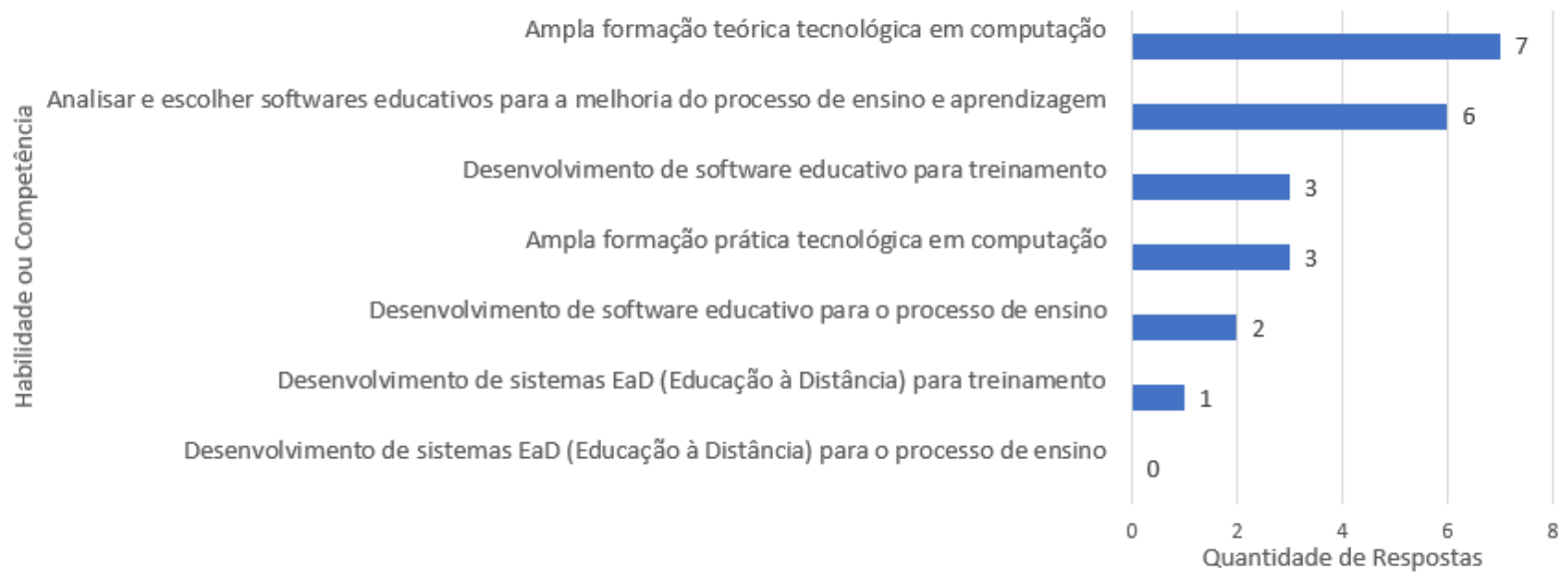

Figura 1: Habilidades/Competências desenvolvidas durante o estágio (Fonte: Autoria própria). 


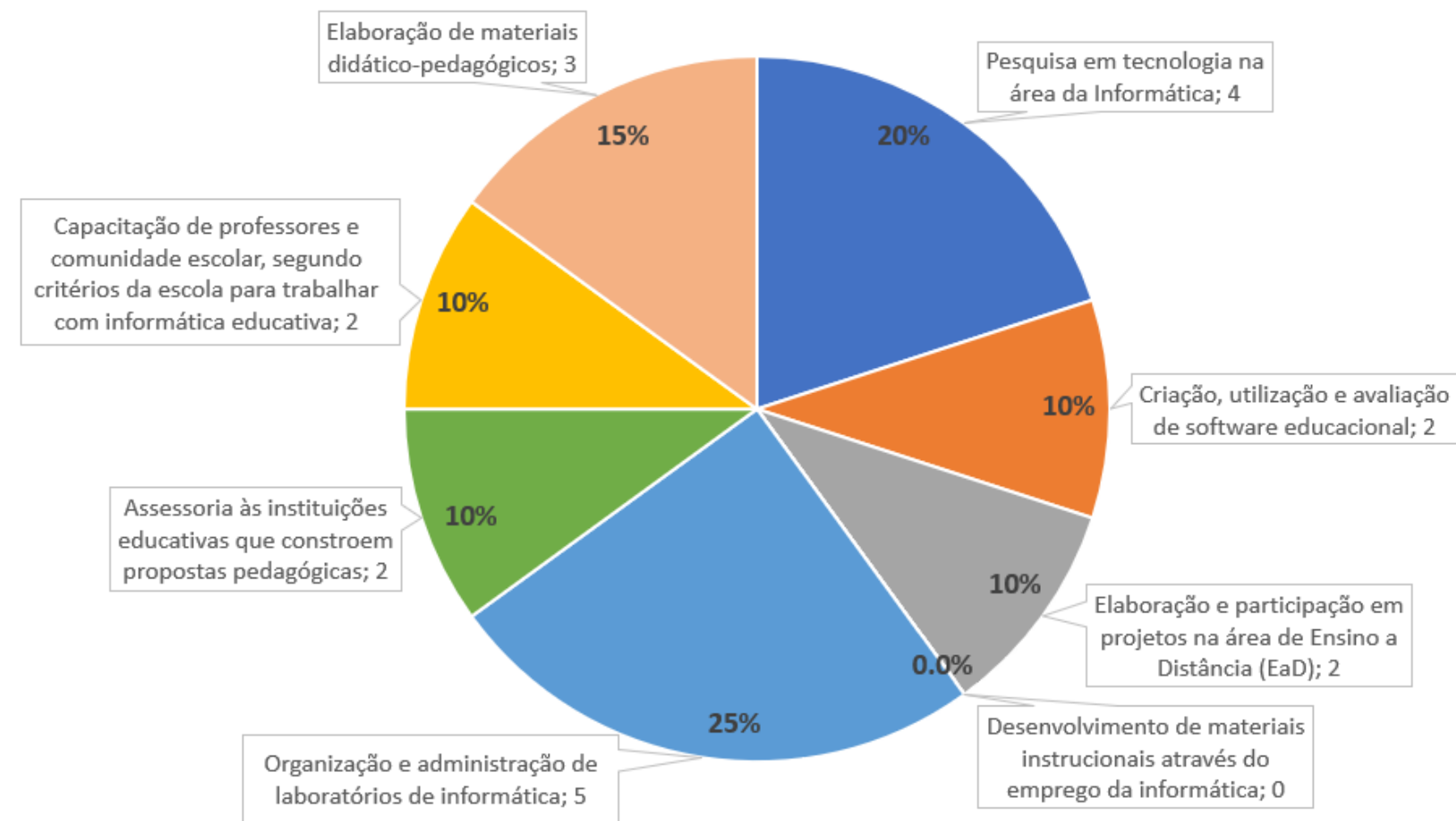

Figura 2: Campos de atuação do estágio (Fonte: Autoria própria).

Finalmente, foi perguntado a todos os licenciandos em quais campos de atuação diferentes dos que foram expostos pelo questionário eles poderiam atuar. As respostas foram sumarizadas no Quadro 2. É possível notar que a maioria dos licenciandos indicou que eles poderiam atuar no "desenvolvimento de sistemas de software" seguido por "prover consultoria pedagógica para a inclusão das TIC no processo de ensino e aprendizagem”.

\subsection{Campo de Atuação dos Egressos (QP2)}

De acordo com a coordenação do curso, foram formados 30 licenciados em Informática/Computação. O questionário foi enviado para 24 licenciados cujo contato foi disponibilizado pela coordenação. Ao total, foram recebidas somente 12 respostas, representando uma amostra de $40 \%$ dos licenciados. Possivelmente a falta de respostas de metade dos licenciados possa indicar a falta de espaços de atuação, conforme discutido por (SANTOS, SILVA \& HINTERHOLZ, 2017). A amostra foi formada por licenciados formados entre os anos de 2013 e 2017 , com idade entre 24 a 50 anos e a maioria deles (75\%) era do sexo masculino.

Quadro 2: Possíveis novos campos de atuação - Visão dos licenciandos.

\begin{tabular}{|l|l|}
\hline \multicolumn{1}{|c|}{ Campos de atuação } & \multicolumn{1}{c|}{ Respostas dos licenciandos } \\
\hline Consultoria pedagógica & $\begin{array}{l}\text { "Um formador fora da sala de aula levando o conhecimento educacional e } \\
\text { tecnológico mesmo fora da sala de aula com palestras e eventos } \\
\text { educacionais." } \\
\text { "Produzir e difundir conhecimentos no campo educacional." }\end{array}$ \\
\hline Desenvolvimento de Sistemas & $\begin{array}{l}\text { "Na área de programação básica." } \\
\text { "Como analista de sistema, criação de software." } \\
\text { "Além da docência a área de programação pra quem gosta." } \\
\text { "Programação e desenvolvimento de projetos de pesquisa." } \\
\text { "pesquisa e desenvolvimento de software." }\end{array}$ \\
\hline
\end{tabular}


Em relação à utilização das TIC na educação, todos os egressos concordaram sobre a importância da inserção das TIC no processo de ensino e aprendizagem, pois "elas fazem parte do nosso cotidiano, seja de forma simples ou não". Esse resultado é convergente com (RAPKIEWICZ et al., 2004), pois compara a habilidade de utilização das TIC com a capacidade de ler e escrever. Além de indicar concordância ou não, os egressos também justificaram a sua respostas. As justificativas foram sintetizadas na Tabela 4. É possível notar que a maioria dos egressos reconhecem que as TIC podem auxiliar na definição de "novas metodologias" para o processo de ensino e aprendizagem e que estão "inseridas no cotidiano" da maioria dos alunos. Entretanto, também reconhecem que as TIC devem ter uma "adequação ao contexto do aluno". De modo geral, os três tópicos extraídos das justificativas dos egressos são complementares e revelam que os egressos possuem uma visão crítica sobre a utilização das TIC no processo de ensino e aprendizagem, ou seja, por mais que as TIC estejam inseridas no cotidiano dos alunos, nem todos eles possuem acesso a elas.

Tabela 4: A importância das TIC no processo de ensino e aprendizagem segundo os licenciandos.

\begin{tabular}{|c|l|l|c|}
\hline \multicolumn{1}{|c|}{ Tópico } & \multicolumn{1}{|c|}{ Exemplo de Resposta dos Egressos } & $\begin{array}{c}\text { Percentual em relação } \\
\text { ao total de respostas }\end{array}$ \\
\hline 1 & Nova metodologia & $\begin{array}{l}\text { "Porque elas oferecem um leque de oportunidades para } \\
\text { diversificar e dinamizar as aulas." }\end{array}$ & $41,7 \%$ \\
\hline 2 & Inserção no cotidiano & $\begin{array}{l}\text { "Atualmente é imprescindível o uso das Tecnologias } \\
\text { no processo ensino-aprendizagem, o mundo está } \\
\text { inteiramente voltado ao seu uso." }\end{array}$ & $41,7 \%$ \\
\hline 3 & $\begin{array}{l}\text { Adequação ao contexto } \\
\text { do aluno }\end{array}$ & $\begin{array}{l}\text { "É notória a necessidade inclusão das tecnologias na } \\
\text { sala de aula, dada a necessidade crescente de } \\
\text { adequação do ensino ao contexto social dos alunos." }\end{array}$ & $16,6 \%$ \\
\hline
\end{tabular}

Sobre a formação recebida para lecionar Computação e Informática nos níveis fundamental, médio e profissionalizante, todos os egressos afirmaram que essa formação foi suficiente, pois "ao longo do curso adquirimos conhecimento teórico e prático para o exercício dessa função em sala de aula, bem como no dia a dia, já que a atribuição do educador se estende à vida particular". Além disso, a formação também abordou Informática educativa, pois "já que todas as disciplinas foram voltadas para o processo de ensino e na maioria teóricas com ferramentas disponível e utilizada no processo de ensino fundamental e médio". Essa formação deve ser aliada com as formações científica e tecnológica (PAIVA et al., 2017), proporcionando uma visão humanística aos egressos em Computação.

Em seguida, para conhecer a formação base do profissional licenciado em Computação, os egressos foram questionados sobre as habilidades/competências que foram desenvolvidas durante o curso. A Tabela 5 apresenta o resultado, indicando que que a maioria dos egressos concorda (totalmente ou parcialmente) que estão (i) adquirindo "ampla formação teórica/prática tecnológica em computação", (ii) desenvolvendo habilidades para "desenvolvimento de sistemas EaD para o processo de ensino e para treinamento", e (iii) sendo preparados para "analisar e escolher softwares educativos para a melhoria do processo de ensino e aprendizagem". Entretanto, os licenciandos evidenciaram que as habilidades "desenvolvimento de software educativo para (i) o processo de ensino e (ii) para treinamento" não foram desenvolvidas completamente no curso. Além disso, 83,3\% dos egressos afirmaram que as disciplinas da matriz curricular cursada por eles foram suficientes para desenvolver as habilidades e competências apresentadas na Tabela 5. Entretanto, eles informaram que o curso deveria ofertar disciplinas para o desenvolvimento de software, focar mais na inclusão das novas tecnologias no ensino médio e profissionalizante. Como pontos de melhorias, foram sugeridos uma "melhoria na estrutura física do polo no que se refere a laboratórios" e "não é colocar disciplina nova, mas modelar as já existentes". 
A Tabela 6 apresenta os campos de atuação que os egressos se sentiam preparados para atuar. Pode-se notar que a maioria dos egressos se sentiam aptos para atuar com a "organização e administração de laboratórios de informática" e a "capacitação de professores e comunidade escolar, segundo critérios da escola para trabalhar com informática educativa".

Tabela 5: Habilidades e competências desenvolvidas - Visão dos egressos.

\begin{tabular}{|c|c|c|c|c|c|}
\hline Habilidades/Competências & DT & DP & IN & $\mathbf{C P}$ & CT \\
\hline Ampla formação teórica tecnológica em computação & 3 & 0 & 0 & 5 & 4 \\
\hline Ampla formação prática tecnológica em computação & 2 & 2 & 0 & 6 & 2 \\
\hline Desenvolvimento de software educativo para o processo de ensino & 2 & 4 & 1 & 2 & 3 \\
\hline Desenvolvimento de software educativo para treinamento & 1 & 5 & 1 & 3 & 2 \\
\hline Desenvolvimento de sistemas EaD (Educação a Distância) para o processo de ensino & 2 & 2 & 0 & 5 & 3 \\
\hline Desenvolvimento de sistemas EaD (Educação a Distância) para treinamento & 1 & 4 & 1 & 4 & 2 \\
\hline $\begin{array}{l}\text { Analisar e escolher softwares educativos para a melhoria do processo de ensino e } \\
\text { aprendizagem }\end{array}$ & 3 & 0 & 0 & 2 & 7 \\
\hline $\begin{array}{l}\text { Legenda: } \\
\text { DT= Discordo totalmente } \\
\text { CP }=\text { Concordo parcialmente }\end{array}$ & \multicolumn{5}{|c|}{$\mathrm{IN}=$ Indiferente } \\
\hline
\end{tabular}

Tabela 6: Campos de atuação aptos a atuar pelos egressos.

\begin{tabular}{|l|c|c|}
\hline \multicolumn{1}{|c|}{ Campos de atuação aptos a atuar } & Quantidade & Percentual \\
\hline Organização e administração de laboratórios de informática & 12 & $100 \%$ \\
\hline $\begin{array}{l}\text { Capacitação de professores e comunidade escolar, segundo critérios da escola } \\
\text { para trabalhar com informática educativa }\end{array}$ & 12 & $100 \%$ \\
\hline Elaboração de materiais didático-pedagógicos & 10 & $86,3 \%$ \\
\hline Assessoria às instituições educativas que constroem Propostas Pedagógicas & 8 & $66,7 \%$ \\
\hline Criação, utilização e avaliação de software educacional & 8 & $66,7 \%$ \\
\hline Elaboração e participação em projetos na área de Ensino a Distância (EAD) & 8 & $66,7 \%$ \\
\hline Desenvolvimento de materiais instrucionais através do emprego da informática & 8 & $66,7 \%$ \\
\hline Pesquisa em tecnologia na área da Informática & 8 & $66,7 \%$ \\
\hline
\end{tabular}

Ainda sobre o campo de atuação, os egressos foram questionados se conseguiram alguma colocação profissional após a conclusão do curso. Dentre eles, 50\% informaram que conseguiram, atuando como tutores presenciais do próprio curso, operador de AVA, técnico de tecnologia da informação, professor de Informática básica e professor do LEI.

Os egressos também indicaram as habilidades que foram desenvolvidas durante o curso que foram utilizadas na sua atuação profissional. A Figura 3 apresenta o resultado, indicando que as habilidades "ampla formação teórica tecnológica em computação" e "analisar e escolher softwares educativos para a melhoria do processo de ensino e aprendizagem" foram as mais desenvolvidas pelos egressos na sua atuação profissional.

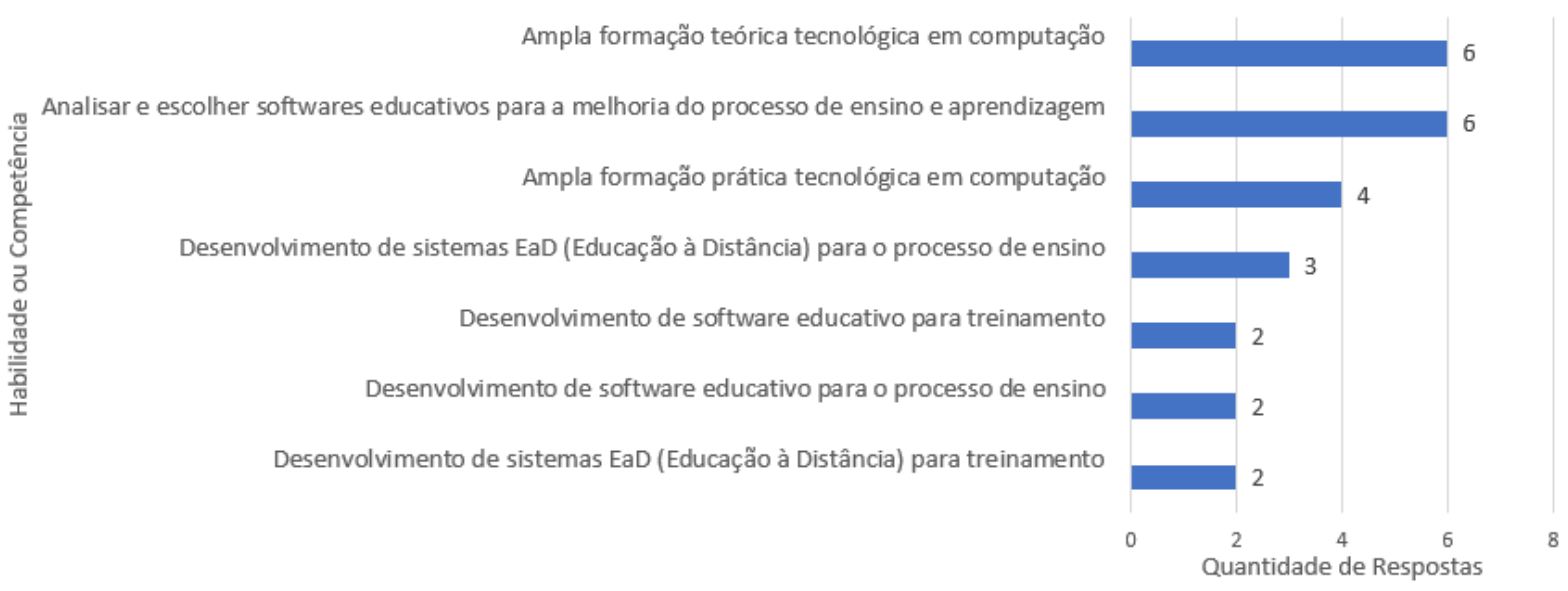

Figura 3: Habilidades/Competências desenvolvidas durante a atuação profissional (Fonte: Autoria própria). 
A Figura 4 mostra os campos de atuação desenvolvidos durante a atuação profissional, conforme indicado pelos egressos. É possível observar que as atuações profissionais ocupadas pelos egressos se enquadravam principalmente em "organização e administração de laboratórios de informática". Vale ressaltar que todos os campos de atuação indicados na Figura 4 foram ocupados por pelo menos um egresso.

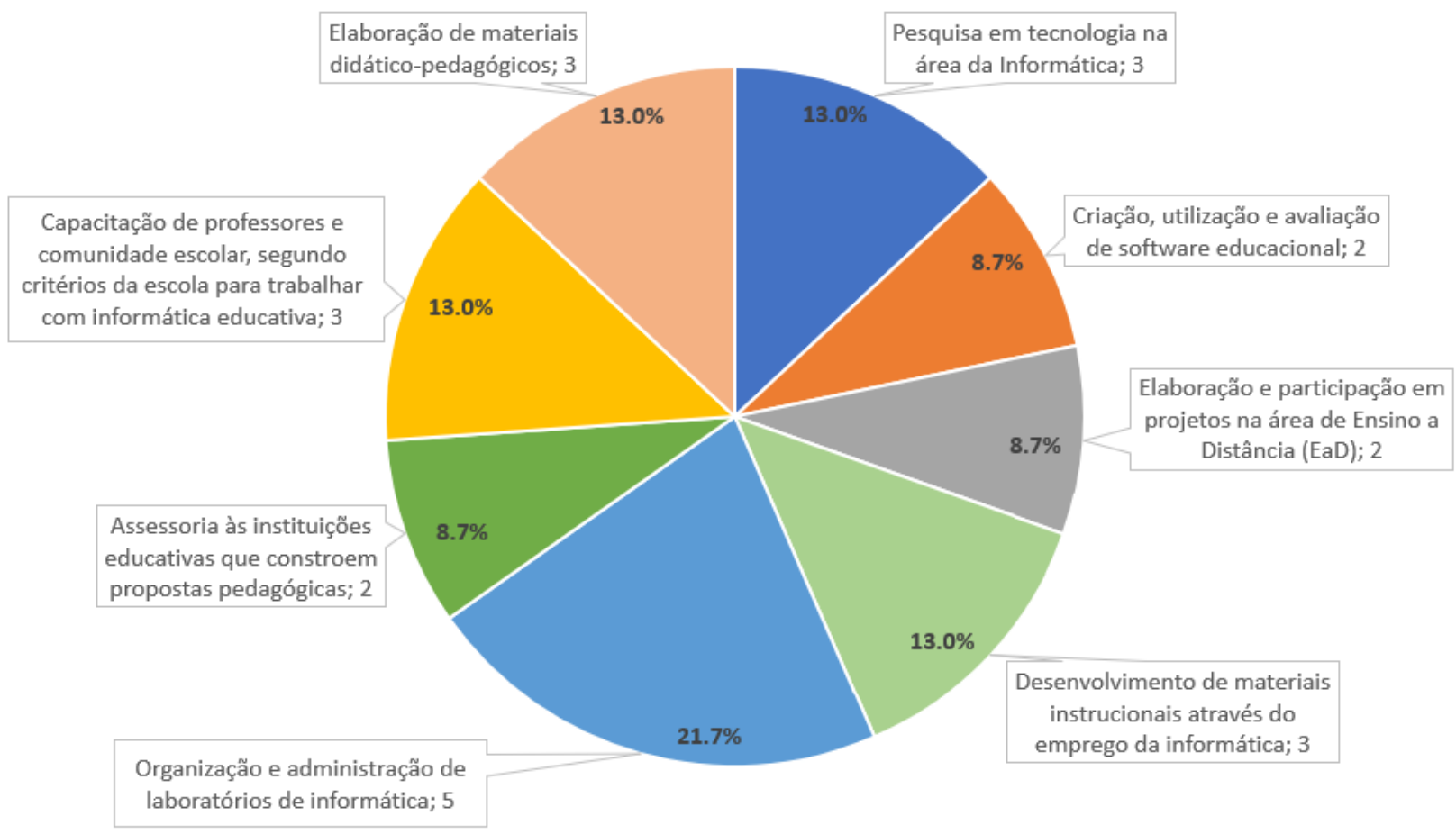

Figura 4: Campos de atuação do mundo do trabalho (Fonte: Autoria própria).

Finalmente, foi perguntado a todos os egressos em quais campos de atuação diferentes dos que foram expostos pelo questionário eles poderiam atuar. As respostas foram sumarizadas no Quadro 3. É possível notar que a maioria dos licenciandos indicou que eles poderiam atuar na "docência do ensino básico e superior" seguido por "exercer funções associadas à tecnologia da informação". Entretanto, um egresso ressalta que "os campos são vastos, nos falta oportunidades para exercermos a nossa profissão, pois, ouvimos muito sobre a importância das tecnologias na educação, porém, os profissionais formados na área não são aproveitados".

Quadro 3: Possíveis novos campos de atuação - Visão dos egressos.

\begin{tabular}{|l|l|}
\hline \multicolumn{1}{|c|}{ Campos de atuação } & \multicolumn{1}{c|}{ Respostas dos licenciandos } \\
\hline Docência do ensino básico e & "Professor do ensino básico e superior." \\
superior & "Nos permite atuar em atividades que necessitem de conhecimentos \\
& científicos em informática/computação." \\
& "Escolas e faculdade" \\
& "Sala de aula, laboratório de informática" \\
& "Segurança para promover o ensino aprendizagem utilizando as TICs." \\
& "Para mim, só na área docente." \\
& "Laboratório." \\
\hline
\end{tabular}




\begin{tabular}{|l|l|}
\hline Tecnologia da Informação & "No campo da tecnologia como na criação de software, por exemplo. Porém, \\
& necessitaria de um treinamento mais específico e com mais tempo de estudo e \\
prática." & "Na área da computação, o campo é amplo e muito flexível, possibilitando \\
assim o licenciado em Computação exercer sua função tanto no âmbito \\
educacional como empresarial." \\
"todos os campos que envolvam tecnologia."
\end{tabular}

\section{Discussão}

Nessa seção é apresenta a síntese dos resultados para responder às questões de pesquisa definidas para esse trabalho. Em seguida, uma comparação entre os campos de atuação esperados e ocupados é descrita. Finalmente, a comparação dos achados do presente trabalho com os reportados pelos trabalhos relacionados é apresentada.

\subsection{Respondendo às Questões de Pesquisa}

Nessa subseção, os resultados são resumidos e discutidos por questão de pesquisa.

\subsubsection{QP1: Quais são os campos de atuação esperados pelos alunos do curso de licenciatura em Computação?}

Por meio da análise das respostas dos licenciandos em Computação foi possível constatar que a inserção das TIC é importante pois proporcionam "novas metodologias de ensino e aprendizagem", são vistas como "tecnologia do cotidiano" e o processo de ensino e aprendizagem deve "se adequar às novas tecnologias". Os licenciandos reconhecem que estão tendo uma boa formação para o exercício da docência em Computação nos diferentes níveis de ensino (fundamental, médio e profissionalizante). Essa formação tem proporcionado principalmente o desenvolvimento das habilidades referentes à "ampla formação teórica/prática tecnológica em computação" e ao "desenvolvimento de sistemas EaD para o processo de ensino e para treinamento". Os campos de atuação esperados pelos licenciandos são referentes à "organização e administração de laboratórios de informática" e à "capacitação de professores e comunidade escolar, segundo critérios da escola para trabalhar com informática educativa".

O estágio tem desenvolvido um papel importante para a formação dos licenciandos em Computação. As habilidades "ampla formação teórica tecnológica em computação" e "analisar e escolher softwares educativos para a melhoria do processo de ensino e aprendizagem" foram as mais desenvolvidas pelos licenciandos que cursaram a disciplina de estágio. Além disso, as principais atividades desenvolvidas no estágio estavam relacionadas à "organização e administração de laboratórios de informática" e à "pesquisa em tecnologia na área de informática". Os licenciandos também indicaram que "consultoria pedagógica" e "desenvolvimento de sistemas" seriam possíveis campos de atuação.

Diante do exposto, pode-se notar que a maioria dos alunos do curso de licenciatura que participaram da pesquisa esperam atuar como professores do LEI. Essa visão se deve principalmente às experiências dos licenciandos obtidas durante o estágio. Além disso, as habilidades desenvolvidas durante o curso e durante o estágio também colaboram para essa visão, pois os professores dos LEI dão suporte aos professores da base comum para integrar as TIC nas suas aulas. Além disso, o colegiado do curso poderia discutir sobre a inclusão dos novos campos de atuação ("consultoria pedagógica" e "desenvolvimento de sistemas") identificados pelos licenciandos. Será que esses novos campos fazem parte da formação esperada para esse profissional? Poderiam auxiliá-los na inserção no mundo do trabalho? Essas perguntas poderiam servir como ponto de partida para a discussão. 


\subsubsection{QP2: Quais são os campos de atuação ocupados pelos egressos do curso de licenciatura em Computação?}

Ao analisar as respostas dos egressos do curso de licenciatura em Computação foi possível verificar que eles acreditam que a inserção das TIC é importante no processo de ensino e aprendizagem pois proporcionam "novas metodologias" e devem ser "inseridas no cotidiano" dos alunos, mas "adequando-se ao contexto dos alunos". Os egressos também reconheceram que a formação recebida foi suficiente para o exercício da docência em Computação nos diferentes níveis de ensino (fundamental, médio e profissionalizante). Essa formação proporcionou principalmente o desenvolvimento das habilidades referentes à "ampla formação teórica/prática tecnológica em computação" e ao "desenvolvimento de sistemas EaD para o processo de ensino". Os campos de atuação que os egressos se sentiam preparados para ocupar eram referentes à "organização e administração de laboratórios de informática" e à "capacitação de professores e comunidade escolar, segundo critérios da escola para trabalhar com informática educativa".

Metade dos egressos participantes da pesquisa conseguiram alguma colocação profissional, atuando como "tutores presenciais do próprio curso", "operador de AVA", "técnico de tecnologia da informação", "professor de Informática básica" e "professor do LEI". Analisando as funções exercidas por eles, é notório que a demanda por esses profissionais advém do próprio curso de licenciatura em Computação, porém outro campo de atuação seria atuar como professor do LEI nas escolas da cidade. As habilidades "ampla formação teórica tecnológica em computação" e "analisar e escolher softwares educativos para a melhoria do processo de ensino e aprendizagem" foram as habilidades mais requeridas no mundo do trabalho. Além disso, as principais atividades desenvolvidas no mundo do trabalho estavam relacionadas à "organização e administração de laboratórios de informática". Os egressos também indicaram que poderiam ministrar aulas no "ensino básico e superior" e exercer atividades relacionadas à "tecnologia da informação".

Assim, pode-se notar que a maioria dos egressos do curso de licenciatura em Computação conseguiu atuar como professor do LEI. Esse posto de trabalho deve ser o mais viável na cidade na qual o polo presencial está inserido, provendo oportunidades para atuar nos outros campos de atuação esperados pelo curso. Além disso, discussões sobre melhorias no PPC poderiam identificar meios para a inserção dos egressos em outros campos de atuação esperados pelo curso. Será que a cidade provê outras oportunidades? O curso de licenciatura em Computação é conhecido na cidade? Esses questionamentos poderiam ser utilizados como ponto de partida para discussão.

\subsection{Campo de Atuação: Perspectiva X Realidade}

A Figura 5 apresenta o comparativo entre a perspectiva dos alunos e a realidade dos egressos do curso de licenciatura em Computação em relação ao campo de atuação. A comparação é feita por meio do percentual calculado entre a soma da citação de um campo de atuação dividido pela sua quantidade total de citações. É possível notar que "organização e administração de laboratórios de informática" é o campo de atuação mais esperado e mais ocupado por $16 \%$ dos licenciandos e $22 \%$ dos egressos do curso de licenciatura de Computação, respectivamente. Além disso, 16\% dos licenciandos também esperam trabalhar na "capacitação de professores e comunidade escolar, segundo critérios da escola para trabalhar com informática educativa". 


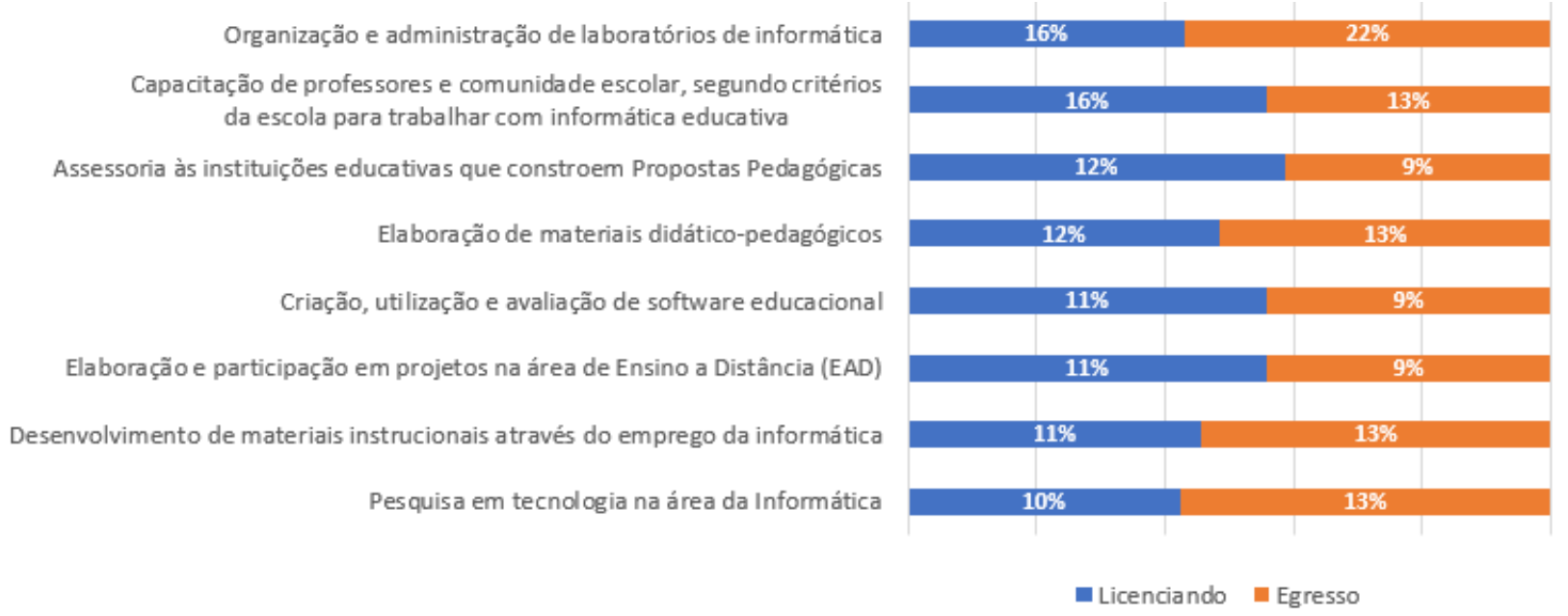

Figura 5: Comparação entre campos de atuação esperados e ocupados (Fonte: Autoria própria).

Ainda analisando a Figura 5, pode-se perceber que os licenciandos esperam trabalhar, como segundo mais citado (12\%), na "assessoria às instituições educativas que constroem Propostas Pedagógicas e na elaboração de materiais didático-pedagógicos". Entretanto, os egressos, como segundo mais citado (13\%), têm trabalhado com a "capacitação de professores e comunidade escolar, segundo critérios da escola para trabalhar com informática educativa", "elaboração de materiais didático-pedagógicos", "desenvolvimento de materiais instrucionais através do emprego da informática" e "pesquisa em tecnologia na área da Informática".

Em suma, o ponto de vista dos licenciandos em Computação e dos egressos do curso é bem similar em relação aos campos de atuação que podem ocupar devido à formação recebida no referido curso. Além disso, foi constatado que os licenciandos são cientes das diversas ocupações que podem ter no mundo do trabalho. Devido à visão similar, as melhorias aplicadas no PPC, seguindo a visão dos egressos pode também atender aos anseios dos licenciandos. Assim, essas melhorias poderiam ser aplicadas no sentido de proporcionar uma melhor inserção dos egressos no mundo do trabalho.

\subsection{Comparação com os Trabalhos Relacionados}

A comparação dos resultados obtidos pelo presente trabalho foi realizada considerando os achados reportados por (AYLA \& ROCHA, 2018; ROMERO, 2017; LUCIANO \& SANTOS, 2013; RAPKIEWICZ et al., 2004). Entretanto, durante a comparação foi percebido que os resultados estavam em níveis de abstração diferentes. Enquanto os resultados do presente trabalho estavam em um nível mais alto (campos de atuação), os encontrados na literatura estavam no nível mais baixo (funções). Por isso, foi necessário uniformizar o nível de abstração possibilitando que todos os achados estivessem no nível mais alto, ou seja, reportassem campos de atuação. Para tanto, cada função reportada nos trabalhos relacionados foi analisada e um dos campos de atuação descritos na Figura 5 foi atribuído. O Quadro 4 apresenta a uniformização dos achados. 
Quadro 4: Uniformização dos achados reportados pelos trabalhos relacionados.

\begin{tabular}{|c|c|c|}
\hline Trabalho & Função & Campo de Atuação \\
\hline \multirow[t]{3}{*}{$\begin{array}{l}\text { RAPKIEWICZ et } \\
\text { al., } 2004\end{array}$} & $\begin{array}{l}\text { Professores de Informática e } \\
\text { Computação }\end{array}$ & $\begin{array}{l}\text { Capacitação de professores e comunidade escolar, } \\
\text { segundo critérios da escola para trabalhar com } \\
\text { informática educativa }\end{array}$ \\
\hline & $\begin{array}{l}\text { Ministrar treinamentos e dar } \\
\text { suporte aos professores para a } \\
\text { utilização das TIC }\end{array}$ & $\begin{array}{l}\text { Capacitação de professores e comunidade escolar, } \\
\text { segundo critérios da escola para trabalhar com } \\
\text { informática educativa }\end{array}$ \\
\hline & $\begin{array}{ll}\text { Ministrar } & \text { treinamento } \\
\text { corporativo } & \end{array}$ & $\begin{array}{l}\text { Capacitação de professores e comunidade escolar, } \\
\text { segundo critérios da escola para trabalhar com } \\
\text { informática educativa }\end{array}$ \\
\hline \multirow[t]{7}{*}{$\begin{array}{l}\text { LUCIANO \& } \\
\text { SANTOS, } 2013\end{array}$} & Educação presencial & $\begin{array}{l}\text { Capacitação de professores e comunidade escolar, } \\
\text { segundo critérios da escola para trabalhar com } \\
\text { informática educativa }\end{array}$ \\
\hline & Educação a distância & $\begin{array}{l}\text { Capacitação de professores e comunidade escolar, } \\
\text { segundo critérios da escola para trabalhar com } \\
\text { informática educativa }\end{array}$ \\
\hline & Desenvolvimento WEB & - \\
\hline & $\begin{array}{l}\text { Manutenção e suporte de } \\
\text { computadores }\end{array}$ & - \\
\hline & Desenvolvimento de software & - \\
\hline & Treinamento coorporativo & $\begin{array}{l}\text { Capacitação de professores e comunidade escolar, } \\
\text { segundo critérios da escola para trabalhar com } \\
\text { informática educativa }\end{array}$ \\
\hline & Gerenciamento de projetos & - \\
\hline \multirow[t]{10}{*}{ ROMERO, 2017} & Administrativa & $\begin{array}{l}\text { Assessoria às instituições educativas que constroem } \\
\text { Propostas Pedagógicas }\end{array}$ \\
\hline & Docência & $\begin{array}{l}\text { Capacitação de professores e comunidade escolar, } \\
\text { segundo critérios da escola para trabalhar com } \\
\text { informática educativa }\end{array}$ \\
\hline & Gestão & $\begin{array}{l}\text { Assessoria às instituições educativas que constroem } \\
\text { Propostas Pedagógicas }\end{array}$ \\
\hline & Docência e administrativa & $\begin{array}{l}\text { Capacitação de professores e comunidade escolar, } \\
\text { segundo critérios da escola para trabalhar com } \\
\text { informática educativa }\end{array}$ \\
\hline & $\begin{array}{l}\text { Coordenadora de polo e de curso } \\
\text { técnico EaD }\end{array}$ & $\begin{array}{l}\text { Assessoria às instituições educativas que constroem } \\
\text { Propostas Pedagógicas }\end{array}$ \\
\hline & Inspetor de alunos & - \\
\hline & $\begin{array}{l}\text { Manutenção e programação de } \\
\text { computadores }\end{array}$ & - \\
\hline & Manutenção de computadores & $\begin{array}{l}\text { Organização e administração de laboratórios de } \\
\text { informática }\end{array}$ \\
\hline & Tecnológico & - \\
\hline & Vendas autônomas. & - \\
\hline $\begin{array}{l}\text { AYLA \& ROCHA, } \\
2018\end{array}$ & $\begin{array}{l}\text { Ser um técnico que gerencia } \\
\text { tecnologias. }\end{array}$ & $\begin{array}{l}\begin{array}{l}\text { Organização e administração de laboratórios de } \\
\text { informática }\end{array} \\
\end{array}$ \\
\hline
\end{tabular}

Analisando o Quadro 4, é possível perceber que as seguintes funções não estão associadas com nenhum dos campos de atuação esperados para os licenciandos e licenciados em Computação: "desenvolvimento WEB", "manutenção e suporte de computadores", "desenvolvimento de software", "gerenciamento de projetos", "inspetor de alunos", "manutenção e programação de computadores", "tecnológico" e "vendas autônomas".

O Quadro 5 apresenta o comparativo entre os campos de atuação encontrados no presente trabalho e os reportados na literatura na visão dos Egressos. Pode-se notar que a ocupação do campo de atuação "capacitação de professores e comunidade escolar, segundo critérios da escola para trabalhar com informática educativa" por egressos do curso de licenciatura em Computação foi encontrado por quase todos os trabalhos. Entretanto, a ocupação dos campos de atuação 
"organização e administração de laboratórios de informática" e "assessoria às instituições educativas que constroem propostas pedagógicas" foi evidenciada por três e dois trabalhos (inclusive pelo presente trabalho). Por outro lado, a ocupação dos campos de atuação "elaboração de materiais didático-pedagógicos", "criação, utilização e avaliação de software educacional", "elaboração e participação em projetos na área de Ensino a Distância (EAD)", "desenvolvimento de materiais instrucionais através do emprego da informática", e "pesquisa em tecnologia na área da Informática" foi identificada somente pelo presente trabalho.

Quadro 5: Comparação com os Trabalhos Relacionados.

\begin{tabular}{|l|c|c|c|c|c|}
\hline \multicolumn{1}{|c|}{ Campos de atuação } & $\begin{array}{c}\text { Presente } \\
\text { Trabalho }\end{array}$ & $\begin{array}{c}\text { RAPKIEWICZ } \\
\text { et al., 2004 }\end{array}$ & $\begin{array}{c}\text { LUCIANO } \\
\text { \& SANTOS, } \\
\mathbf{2 0 1 3}\end{array}$ & $\begin{array}{c}\text { ROMERO, } \\
\mathbf{2 0 1 7}\end{array}$ & $\begin{array}{c}\text { AYLA \& } \\
\text { ROCHA, } \\
\mathbf{2 0 1 8}\end{array}$ \\
\hline $\begin{array}{l}\text { Organização e administração de } \\
\text { laboratórios de informática }\end{array}$ & Sim & Não & Não & Sim & Não \\
\hline $\begin{array}{l}\text { Capacitação de professores e } \\
\text { comunidade escolar, segundo } \\
\text { critérios da escola para trabalhar } \\
\text { com informática educativa }\end{array}$ & Sim & Sim & Não & Sim & Não \\
\hline $\begin{array}{l}\text { Assessoria às instituições } \\
\text { educativas que constroem } \\
\text { Propostas Pedagógicas }\end{array}$ & Sim & Não & Não & Não & Não \\
\hline $\begin{array}{l}\text { Elaboração de materiais didático- } \\
\text { pedagógicos }\end{array}$ & Sim & Não & Não & Não & Não \\
\hline $\begin{array}{l}\text { Criação, utilização e avaliação de } \\
\text { software educacional }\end{array}$ & Sim & Não & Não & Não & Não \\
\hline $\begin{array}{l}\text { Elaboração e participação em } \\
\text { projetos na área de Ensino a } \\
\text { Distância (EAD) }\end{array}$ & Sim & Não & Não & Não & Não \\
\hline $\begin{array}{l}\text { Desenvolvimento de materiais } \\
\text { instrucionais através do emprego } \\
\text { da informática }\end{array}$ & Sim & Não & Não & Não & Não \\
\hline $\begin{array}{l}\text { Pesquisa em tecnologia na área da } \\
\text { Informática }\end{array}$ & Sim & Não & & São \\
\hline
\end{tabular}

Em suma, os achados do presente trabalho confirmam e estendem os resultados reportados nos trabalhos relacionados analisados, trazendo uma visão mais abrangente sobre os campos de atuação dos egressos do curso de licenciatura em Computação. Além disso, o presente trabalho apresenta a perspectiva dos licenciandos em relação aos possíveis campos de atuação. Esse tópico não tinha sido ainda explorado pela literatura. Embora (ROMERO, 2017) tivesse coletado dados dos licenciandos, a análise apresentada por esses autores não diferenciou a visão dos licenciandos e dos egressos do referido curso.

\section{Limitações do Estudo}

Por se tratar de um estudo empírico, ameaças à validade ou limitações podem estar presentes desde o processo de definição do método de pesquisa até o procedimento de análise de dados. Portanto, as limitações foram identificadas de acordo com a taxonomia definida por (WOHLIN et al., 2012): interna, externa, construção e conclusão.

Interna: Uma ameaça à validade interna surgiu a partir dos questionários utilizados. Como os licenciandos e egressos do curso de licenciatura em Computação responderam de forma remota, as questões poderiam ser mal interpretadas por eles. Para mitigar essa ameaça, os questionários foram elaborados pelo primeiro autor do presente estudo considerando o PPC do curso analisado. Para avaliar o questionário, um pesquisador experiente (segundo autor) revisou e ajustou todas as 
questões antes da aplicação dos questionários. Mesmo com esse processo de revisão, alguma ameaça ainda pode afetar o estudo, visto que o ideal seria a aplicação de um teste piloto com licenciandos e egressos para realizar possíveis ajustes nas questões.

Externa: Em relação à generalização dos resultados, embora as amostras representem boa parte da população de licenciandos e egressos do curso de licenciatura em Computação ofertado no polo presencial utilizado como local de pesquisa, os resultados encontrados são limitados a esse polo. Portanto, novas replicações dos questionários podem ser conduzidas em outras cidades nas quais o curso de licenciatura em Computação é ofertado para aumentar a validade externa dos resultados.

Construção: Uma ameaça a construção surgiu devido ao perfil dos participantes, pois alunos ou egressos de outros cursos poderiam responder ao questionário. Para reduzir essa ameaça, foram convidados somente licenciandos e licenciados em Computação do referido polo.

Conclusão: Uma ameaça associada à análise das questões abertas do questionário poderia afetar a validade de conclusão do presente estudo. Para reduzir essa ameaça, a análise qualitativa das questões abertas foi realizada pelo primeiro autor e revisada pelo segundo autor. Quando alguma divergência ocorreu, os dois autores se reuniram para resolvê-la.

\section{Considerações Finais}

O presente estudo tem como objetivo desvelar os campos de atuação esperados pelos licenciandos em Computação e os ocupados pelos egressos do referido curso. Por meio de análises quantitativa e qualitativa, identificou-se se a visão dos licenciandos e egressos sobre os campos de atuação eram convergentes. Além disso, os resultados encontrados confirmam e expandem os campos de atuação reportados na literatura.

Em relação ao curso oferecido pela UECE, a formação do licenciado em Computação é aderente às necessidades da cidade, porém, segundo os licenciandos e egressos, outros campos de atuação poderiam ser ocupados por eles, como: consultor pedagógica, desenvolvedor de sistemas, docente do ensino superior e técnico de tecnologia da informação. Os resultados obtidos no presente estudo serão disponibilizados para a coordenação do curso para iniciar discussões sobre melhorias no referido curso.

Como trabalhos futuros, sugere-se a aplicação dos questionários em outros polos presenciais que ofertem o curso de licenciatura em Computação para aumentar a validade externa dos resultados. Além disso, outros fatores, como diferenças nos PPC dos cursos, aspectos das cidades nas quais os cursos são ofertados ou procura-se por ocupação, oportunidades reais do mundo do trabalho, também podem ser analisados com o intuito de identificar se interferem nos campos de atuação de seus licenciandos e egressos.

\section{Agradecimentos}

O presente trabalho foi realizado com apoio da Coordenação de Aperfeiçoamento de Pessoal de Nível Superior - Brasil (CAPES) - Código de Financiamento 001. Os autores agradecem ao polo de apoio presencial de Mauriti/CE por disponibilizar os contatos dos egressos do curso e aos participantes da pesquisa por responder voluntariamente aos questionários propostos. 


\section{Referências}

Araújo, D. F. (2010). O curso de licenciatura em computação do campus VII da UEPB sob a visão dos discentes. Trabalho de Conclusão de Curso (Graduação em Computação) - Universidade Estadual da Paraíba, Patos, 2010. Disponível em: http://dspace.bc.uepb.edu.br/jspui/handle/123456789/2959 [GS Search]

Ayla, L. A., \& Rocha, E. M. (2018). O curso de licenciatura em computação e o campo de atuação profissional: O que dizem seus egressos. In CIETEnPED 2018 Congresso Internacional de Educação e Tecnologias/Encontro de Pesquisadores em Educação a Distância. Disponível em: http://cietenped.ufscar.br/submissao/index.php/2018/article/download/306/375/

Bastos, F. A. A., \& Felipe, M. W. F. (2014). Projeto político pedagógico licenciatura em computação a distância. Fortaleza: UECE. Disponível em: http://www.uece.br/computacaoead/index.php/downloads/doc download/2052pcccomputacao

Castro, C. S., \& Vilarim, G. O. (2013). Licenciatura em computação no cenário nacional: embates, institucionalização e o nascimento de um novo curso. In Revista Espaço Acadêmico, 13(148), $18-25$. Disponível

em: http://www.periodicos.uem.br/ojs/index.php/EspacoAcademico/article/view/21635 [GS $\underline{\text { Search }]}$

Cruz, M. K., Becker, F., \& Hinterholz, L. (2016). Carga horária prática na formação de professores de computação e informática educativa. In Anais do Workshop de Informática na Escola. Uberlândia: Sociedade Brasileira de Computação, 2016, p. 698-706. DOI: 10.5753/cbie.wie.2016.698 [GS Search]

Freitas, L. L. A., \& Freire, E. S. S. (2018). Uma investigação sobre o campo de atuação dos licenciados em computação do polo de apoio presencial em Mauriti/CE. In Anais dos Workshops do VII Congresso Brasileiro de Informática na Educação. Fortaleza: Sociedade Brasileira de Computação, 2018. p. 1042-1051. DOI: 10.5753/cbie.wcbie.2018.1042 [GS Search]

Joye, C.R. (2014). Metodologia científica. Fortaleza: SETEC/IFCE, 2014.

Luciano, A. P. C., \& Santos, A. A. (2013). Caminhos do licenciado em computação no Brasil: Estudo de mercado a partir de uma pesquisa com egressos. In: Anais do II Congresso Brasileiro de Informática na Educação. Campina Grande: Universidade Estadual da Paraíba, 2013. p. 517-526. DOI: $10.5753 /$ cbie.sbie.2013.517 [GS Search]

Matos, E., \& Silva, G. F. B. (2012). Currículo de licenciatura em computação: Uma reflexão sobre perfil de formação à luz dos referenciais curriculares da SBC. In XXXII Congresso da Sociedade Brasileira de Computação - XX Workshop de Educação em Computação. Porto Alegre: SBC, 2012. [GS Search]

Miranda, G. L. (2007). Limites e possibilidades das TIC na educação. Lisboa: Sísifo, 2007. Disponível em: http://sisifo.ie.ulisboa.pt/index.php/sisifo/article/view/60 [GS Search]

Oliveira, W., França, R., Lemos, A., da Cruz, M., Scaico, P., Amaral, H., \& Teixeira, L. (2020). Os desafios enfrentados pela licenciatura em computação que a comunidade de educação em computação precisa conhecer. In: Anais do XXVIII Workshop sobre Educação em Computação. Porto Alegre: Sociedade Brasileira de Computação, 2020. p. 191-195. DOI: $\underline{10.5753 / \text { wei.2020.11156 [GS Search] }}$

Paiva, F. P., Bompet, P., Corlett, E. F., Matos, E., \& Schwarzelmuller, A. (2017). A formação, o trabalho e a identidade profissional do professor de computação: Um mapeamento sobre a 
licenciatura em computação. In Anais dos Workshops do VI Congresso Brasileiro de Informática na Educação. Salvador: Sociedade Brasileira de Computação, 2017. p. 893-901. DOI: $\underline{10.5753 / \mathrm{cbie} . w c b i e .2017 .893}$ [GS Search]

Públio Junior, C. (2018). Formação docente frente as novas tecnologias: Desafios e possibilidades. Intermeio: Revista do Programa de Pós-Graduação em Educação, Campo Grande, MS, v. 47, n. 24, p. 189-210, 2018. Disponível em: https://desafioonline.ufms.br/index.php/intm/article/view/5910 [GS Search]

Queiroz, P., Santos, H., \& Rodrigues, A. (2016). Relato de experiência no PIBID: Projeto interdisciplinar envolvendo Licenciandos em computação e pedagogia no ensino fundamental. In Anais do Workshop de Informática na Escola. Uberlândia: Sociedade Brasileira de Computação, 2016. p. 963-967. DOI: 10.5753/cbie.wie.2016.963 [GS Search]

Rapkiewicz, C. E., Xexéo, J. A. M., Freitas, M. F., Souza, I. F., Delgado, C. A. D. M., \& Campos, M. F. O. (2004). O campo de atuação para licenciandos em computação: Um estudo de caso no Norte Fluminense. In Anais do XXIV Congresso da Sociedade Brasileira de Computação. Rio de Janeiro: Universidade Estadual do Norte Fluminense, 2004. p. 1-11. Disponível em: http://jacarepagua.dcc.ufrj.br/ ladybug/artigos/rapkiewicz.pdf [GS Search]

Romero, R. S. (2017). Estudo sobre o campo de atuação dos concluintes e egressos do curso de licenciatura em computação da EaD/UFGD. 2017. Trabalho de Conclusão de Curso (Bacharelado em Sistemas de Informação) - Faculdade de Ciências Exatas e Tecnologias, Universidade Federal da Grande Dourados, Dourados, MS, 2017. Disponível em: http://repositorio.ufgd.edu.br/jspui/handle/prefix/2888 [GS Search]

Santos, N., Pontes, D. N., Santos, L., \& Hounsell, J. (2016). Softwares educacionais: O papel do licenciado em Computação na escola. In Anais dos Workshops do Congresso Brasileiro de Informática na Educação. Uberlândia: Sociedade Brasileira de Computação, 2016. p. 363366. DOI: $10.5753 /$ cbie.wcbie.2016.363 [GS Search]

Santos, W. O., Silva, C. C. V., \& Hinterholz, L. T. (2017). Licenciatura em computação: Desafios e oportunidades na perspectiva do estudante. In Anais do VI Congresso Brasileiro de Informática na Educação. Recife: Sociedade Brasileira de Computação, 2017. p. 885-894. DOI: $\underline{10.5753 / \text { cbie.wie.2017.885 [GS Search] }}$

Strauss, A., \& Corbin, J. M. (1998). Basics of qualitative research: Techniques and procedures for developing grounded theory. Sage Publications [GS Search]

Teixeira, L. P. (2019). Perfil e inserção profissional do licenciado em computação no Brasil. In Anais do Workshop de Informática na Escola. Brasília: Sociedade Brasileira de Computação, 2019. p. 849-858. DOI: 10.5753/cbie.wie.2019.849 [GS Search]

Xavier, M. C., Teixeira, C. R., \& Saveti, B. P. (2010). Aplicação das tecnologias da informação e comunicação (TICS) na educação e os desafios do educador. Dialogia, São Paulo, v. 9, n. 1, p.105-115, fev. 2010. DOI: 10.5585/dialogia.v9i1.2348 [GS Search]

Wohlin, C., Runeson, P., Höst, M., Ohlsson, M. C., Regnell, B., \& Wesslén, A. (2012). Experimentation in software engineering: An introduction. Springer. [GS Search] 


\section{Apêndice}

\section{A. Questionário aplicado aos Licenciandos}

IDADE: $\quad$ SEXO:

FORMAÇÃO ACADÊMICA (Especificar):

Graduação:

Semestre:

1. Você considera importante a inserção das Tecnologias da Informação e Comunicação (TICs) no processo de ensino-aprendizagem? ( ) Sim ( ) Não Justificativa:

2. Você considera que o Curso de Graduação Licenciatura em Computação a distância forma um educador, capacitado para o ensino de computação e informática no ensino fundamental, médio e profissionalizante? ( ) Sim ( ) Não Justificativa:

3. Acredita que o Curso de Graduação Licenciatura em Computação a distância forma um profissional apto ao exercício da atividade docente na área da Computação, com formação em informática educativa? ( ) Sim ( ) Não Justificativa:

4. Marque uma opção para cada uma das habilidades/competências apresentadas abaixo que você considera que é desenvolvida durante o Curso:

\begin{tabular}{|c|c|c|c|c|c|}
\hline & $\begin{array}{l}\text { Discordo } \\
\text { totalmente }\end{array}$ & $\begin{array}{l}\text { Discordo } \\
\text { parcialmente }\end{array}$ & Indiferente & $\begin{array}{l}\text { Concordo } \\
\text { parcialmente }\end{array}$ & $\begin{array}{l}\text { Concordo } \\
\text { totalmente }\end{array}$ \\
\hline $\begin{array}{l}\text { Ampla formação } \\
\text { teórica } \\
\text { tecnológica em } \\
\text { computação }\end{array}$ & & & & & \\
\hline $\begin{array}{l}\text { Ampla formação } \\
\text { prática } \\
\text { tecnológica em } \\
\text { computação }\end{array}$ & & & & & \\
\hline $\begin{array}{l}\text { Desenvolvimento } \\
\text { de } \quad \text { software } \\
\text { educativo para o } \\
\text { processo } \\
\text { ensino }\end{array}$ & & & & & \\
\hline $\begin{array}{l}\text { Desenvolvimento } \\
\text { de software } \\
\text { educativo para } \\
\text { treinamento }\end{array}$ & & & & & \\
\hline \begin{tabular}{lr}
\multicolumn{2}{l}{ Desenvolvimento } \\
de sistemas & EaD \\
(Educação & a \\
Distância) & para o \\
processo & de \\
ensino & \\
\end{tabular} & & & & & \\
\hline $\begin{array}{l}\text { Desenvolvimento } \\
\text { de sistemas EaD }\end{array}$ & & & & & \\
\hline
\end{tabular}




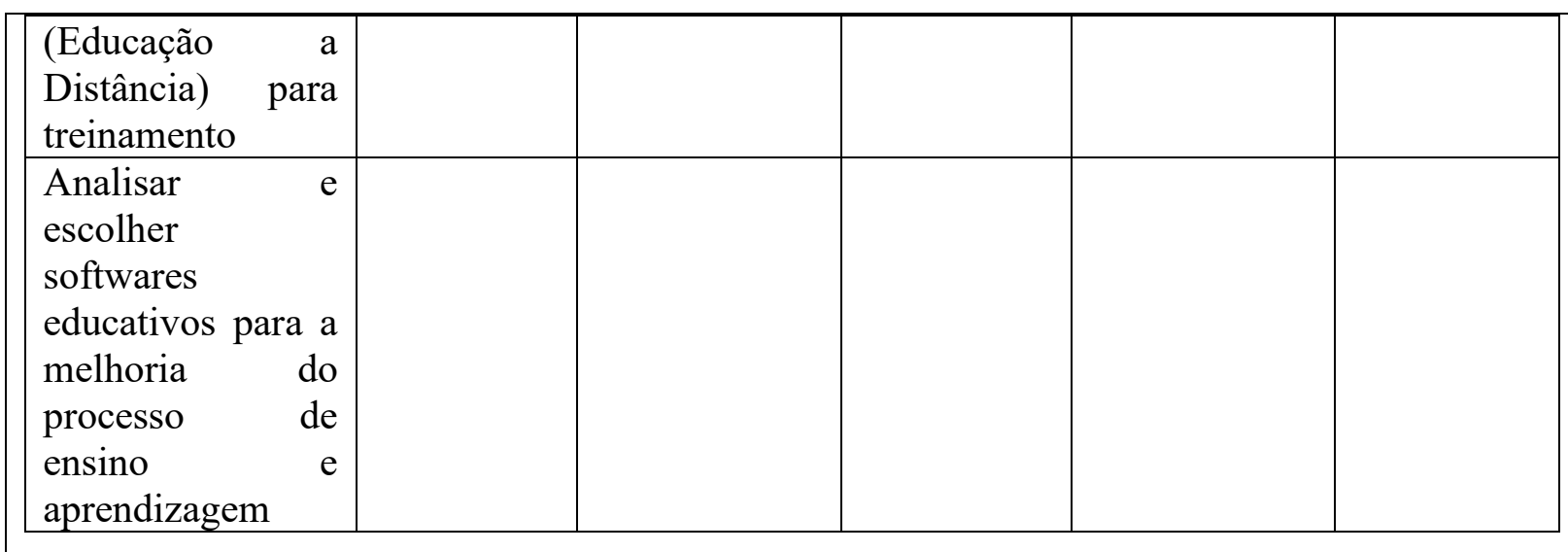

5. Você acredita que as disciplinas que compõem a matriz curricular do seu curso são suficientes para desenvolver as habilidades/competências listadas na questão 4? ( ) Sim ( ) Não

6. Se você respondeu NÃO na questão anterior, quais as disciplinas que poderiam ser incluídas no curso para desenvolver as habilidade e competências apresentadas na questão 4 ?

7. Na sua opinião, quais os possíveis campos de atuação dos alunos do Curso de Graduação Licenciatura em Computação a distância? OBS.: Pode marcar mais de um item, caso necessário.

( ) Pesquisa em tecnologia na área da Informática.

( ) Criação, utilização e avaliação de software educacional.

( ) Elaboração e participação em projetos na área de Ensino a Distância (EAD).

( ) Desenvolvimento de materiais instrucionais através do emprego da informática.

( ) Organização e administração de laboratórios de informática.

( ) Assessoria às instituições educativas que constroem Propostas Pedagógicas.

( ) Capacitação de professores e comunidade escolar, segundo critérios da escola para trabalhar com informática educativa.

( ) Elaboração de materiais didático-pedagógicos.

8. Você já cursou alguma disciplina de estágio? ( ) Sim （ ) Não

9. Caso tenha respondido SIM na questão 8 , relate como foi o seu estágio. Informe qual era a escola, qual foi a turma e quais foram as ações desenvolvidas.

10. Caso tenha respondido SIM na questão 8 , quais as habilidades/competências que você desenvolveu durante o estágio? Pode marcar mais de um, caso seja necessário.

\begin{tabular}{|l|l|}
\hline Habilidade/Competência & Foi desenvolvida? \\
\hline Ampla formação teórica tecnológica em computação & ( ) Sim ( ) Não \\
\hline Ampla formação prática tecnológica em computação & ( ) Sim ( ) Não \\
\hline Desenvolvimento de software educativo para o processo de ensino & ( ) Sim ( ) Não \\
\hline Desenvolvimento de software educativo para treinamento & ( ) Sim ( ) Não \\
\hline $\begin{array}{l}\text { Desenvolvimento de sistemas EaD (Educação a Distância) para o } \\
\text { processo de ensino }\end{array}$ & ( ) Sim ( ) Não \\
$\begin{array}{l}\text { Desenvolvimento de sistemas EaD (Educação a Distância) para } \\
\text { treinamento }\end{array}$ & $($ ) Sim ( ) Não \\
\hline $\begin{array}{l}\text { Analisar e escolher softwares educativos para a melhoria do } \\
\text { processo de ensino e aprendizagem }\end{array}$ & $($ ) Sim ( ) Não \\
\hline
\end{tabular}

11. Caso tenha respondido SIM na questão 8, o seu estágio se enquadra em qual campo de atuação? Pode marcar mais de um, caso seja necessário.

\begin{tabular}{|l|l|}
\hline Campo de Atuação & Foi desenvolvida? \\
\hline Pesquisa em tecnologia na área da Informática. & $(\quad) \operatorname{Sim}(\quad)$ Não \\
\hline
\end{tabular}




\begin{tabular}{|l|l|}
\hline Criação, utilização e avaliação de software educacional. & ( ) Sim ( ) Não \\
\hline $\begin{array}{l}\text { Elaboração e participação em projetos na área de Ensino a Distância } \\
\text { (EAD). }\end{array}$ & ( ) Sim ( ) Não \\
\hline $\begin{array}{l}\text { Desenvolvimento de materiais instrucionais através do emprego da } \\
\text { informática. }\end{array}$ & ( ) Sim ( ) Não \\
\hline Organização e administração de laboratórios de informática. & ( ) Sim ( ) Não \\
\hline $\begin{array}{l}\text { Assessoria às instituiços educativas que constroem Propostas } \\
\text { Pedagógicas. }\end{array}$ & ( ) Sim ( ) Não \\
\hline $\begin{array}{l}\text { Capacitação de professores e comunidade escolar, segundo critérios } \\
\text { da escola para trabalhar com informática educativa. }\end{array}$ & ( ) Sim ( ) Não \\
\hline Elaboração de materiais didático-pedagógicos. & ( ) Sim ( ) Não \\
\hline $\begin{array}{l}\text { 12. Na sua opinião, quais os outros campos de atuação que os alunos poderiam atuar? Justifique } \\
\text { sua resposta. }\end{array}$
\end{tabular}

\section{B. Questionário aplicado aos Egressos}

IDADE: SEXO:

\section{FORMAÇÃO ACADÊMICA}

Graduação:

Polo:

Ano de conclusão do curso:

1. Você considera importante a inserção das Tecnologias da Informação e Comunicação (TICs) no processo de ensino-aprendizagem? ( ) Sim ( ) Não Justificativa:

2. Você considera que o Curso de Graduação Licenciatura em Computação a distância lhe formou como um educador, capacitado para o ensino de computação e informática no ensino fundamental, médio e profissionalizante? ( ) Sim ( ) Não Justificativa:

3. Acredita que o Curso de Graduação Licenciatura em Computação a distância lhe formou como um profissional apto ao exercício da atividade docente na área da Computação, com formação em informática educativa? ( ) Sim ( ) Não Justificativa:

4. Marque uma opção para cada uma das habilidades/competências apresentadas abaixo que você considera que foi desenvolvida durante o curso:

\begin{tabular}{|l|l|l|l|l|l|}
\hline & $\begin{array}{l}\text { Discordo } \\
\text { totalmente }\end{array}$ & $\begin{array}{l}\text { Discordo } \\
\text { parcialmente }\end{array}$ & Indiferente & $\begin{array}{l}\text { Concordo } \\
\text { parcialmente }\end{array}$ & $\begin{array}{l}\text { Concordo } \\
\text { totalmente }\end{array}$ \\
\hline $\begin{array}{l}\text { Ampla formação } \\
\text { teórica } \\
\text { tecnológica em } \\
\text { computação }\end{array}$ & & & & \\
\hline $\begin{array}{l}\text { Ampla formação } \\
\text { prática } \\
\text { tecnológica em } \\
\text { computação }\end{array}$ & & & & & \\
\hline $\begin{array}{l}\text { Desenvolvimento } \\
\text { de software } \\
\text { educativo para o }\end{array}$ & & & & & \\
\hline
\end{tabular}




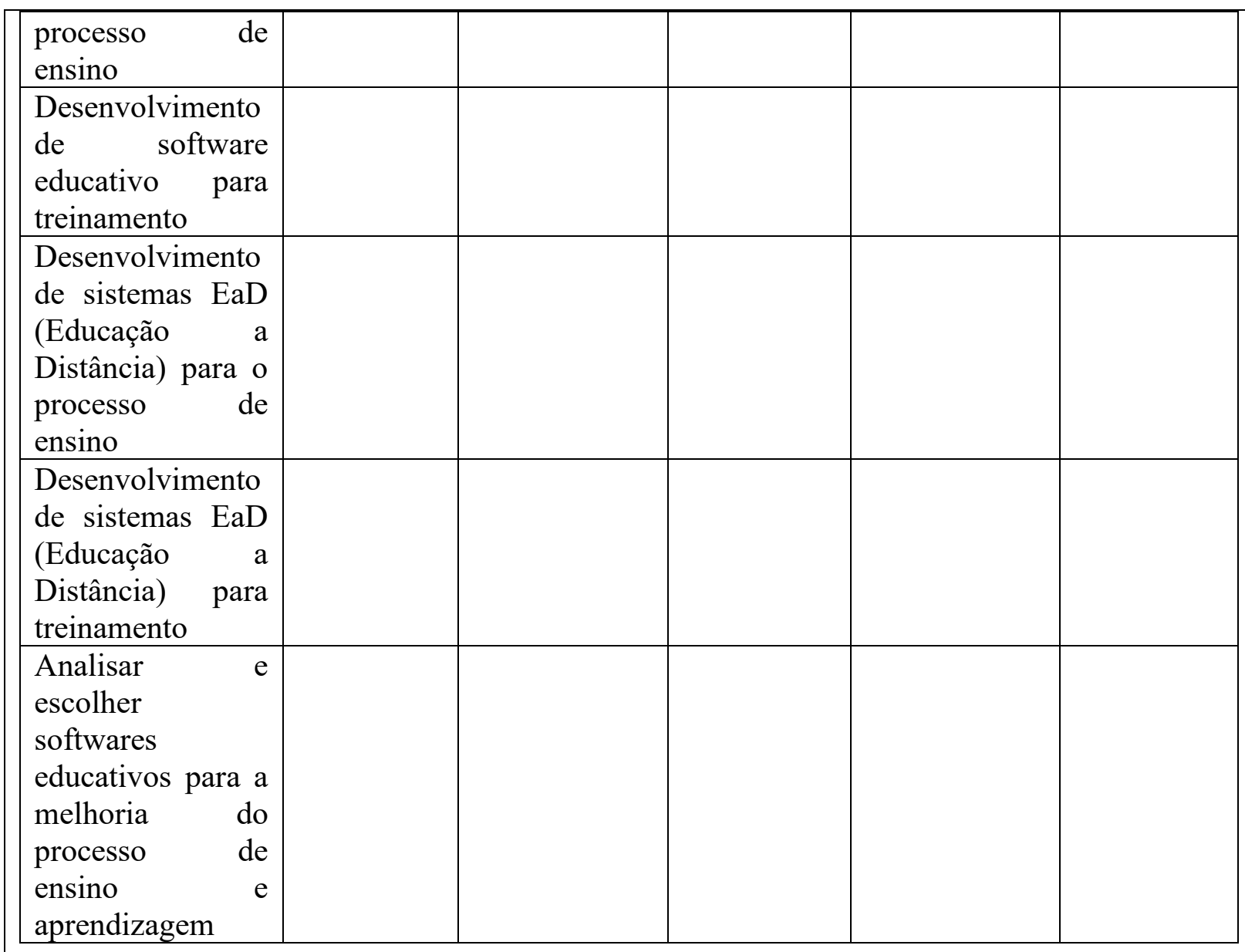

5. Você acredita que as disciplinas contidas na matriz curricular do seu curso são suficientes para desenvolver as habilidades/competências listadas na questão 6? ( ) Sim ( ) Não

6. Se você respondeu NÃO na questão anterior, quais as disciplinas que poderiam ser incluídas no curso para desenvolver as habilidade e competências apresentadas na questão 4 ?

7. Na sua opinião, o curso lhe preparou para atuar em quais dos seguintes campos? OBS.: Pode marcar mais de um item, caso necessário.

( ) Pesquisa em tecnologia na área da Informática.

( ) Criação, utilização e avaliação de software educacional.

( ) Elaboração e participação em projetos na área de Ensino a Distância (EAD).

( ) Desenvolvimento de materiais instrucionais através do emprego da informática.

( ) Organização e administração de laboratórios de informática.

( ) Assessoria às instituições educativas que constroem Propostas Pedagógicas.

( ) Capacitação de professores e comunidade escolar, segundo critérios da escola para trabalhar com informática educativa.

( ) Elaboração de materiais didático-pedagógicos.

8. Após o término do curso, você conseguiu alguma colocação profissional (emprego)?

( ) $\operatorname{Sim}$ ( ) Não

9. Caso tenha respondido SIM na questão 8 , relate quais as atividades que você desenvolve/desenvolveu no seu emprego. Informe qual era a escola/empresa, a duração e quais foram as ações desenvolvidas.

10. Caso tenha respondido SIM na questão 8 , quais as habilidades/competências que você desenvolveu durante o seu emprego? Pode marcar mais de um, caso seja necessário. 


\begin{tabular}{|l|l|}
\hline Habilidade/Competência & Foi desenvolvida? \\
\hline Ampla formação teórica tecnológica em computação & ( ) Sim ( ) Não \\
\hline Ampla formação prática tecnológica em computação & ( ) Sim ( ) Não \\
\hline Desenvolvimento de software educativo para o processo de ensino & ( ) Sim ( ) Não \\
\hline Desenvolvimento de software educativo para treinamento & ( ) Sim ( ) Não \\
\hline $\begin{array}{l}\text { Desenvolvimento de sistemas EaD (Educação a Distância) para o } \\
\text { processo de ensino }\end{array}$ & ( ) Sim ( ) Não \\
\hline $\begin{array}{l}\text { Desenvolvimento de sistemas EaD (Educação a Distância) para } \\
\text { treinamento }\end{array}$ & ( ) Sim ( ) Não \\
\hline $\begin{array}{l}\text { Analisar e escolher softwares educativos para a melhoria do } \\
\text { processo de ensino e aprendizagem }\end{array}$ & ( ) Sim ( ) Não \\
\hline
\end{tabular}

11. Caso tenha respondido SIM na questão 8 , o seu emprego se enquadra em qual campo de atuação? Pode marcar mais de um, caso seja necessário.

\begin{tabular}{|l|l|}
\hline Campo de Atuação & Enquadra-se? \\
\hline Pesquisa em tecnologia na área da Informática. & ( ) Sim ( ) Não \\
\hline Criação, utilização e avaliação de software educacional. & ( ) Sim ( ) Não \\
\hline $\begin{array}{l}\text { Elaboração e participação em projetos na área de Ensino a Distância } \\
\text { (EAD). }\end{array}$ & ( ) Sim ( ) Não \\
\hline $\begin{array}{l}\text { Desenvolvimento de materiais instrucionais através do emprego da } \\
\text { informática. }\end{array}$ & ( ) Sim ( ) Não \\
\hline Organização e administração de laboratórios de informática. & $($ ) Sim ( ) Não \\
\hline $\begin{array}{l}\text { Assessoria às instituições educativas que constroem Propostas } \\
\text { Pedagógicas. }\end{array}$ & ( ) Sim ( ) Não \\
\hline $\begin{array}{l}\text { Capacitação de professores e comunidade escolar, segundo critérios } \\
\text { da escola para trabalhar com informática educativa. }\end{array}$ & $($ ) Sim ( ) Não \\
\hline Elaboração de materiais didático-pedagógicos. & $($ ) Sim ( ) Não \\
\hline Outros: & \\
\hline
\end{tabular}

12. Na sua opinião, quais os outros campos de atuação que o curso the deu condições para atuar? Justifique sua resposta. 